\title{
La reforma del Estado mexicano
}

\section{Luis F. Aguilar Villanueva*}

Los últimos doce años en México han sido todo un giro en las relaciones políticas y en la manera de entender y realizar la función pública. Han sido años de problemas, tensiones, exploraciones, pero también un tiempo de aprendizaje y cambio institucional. La crisis fiscal del Estado y el colapso de la economía nacional a principios de los años ochenta sacudieron la forma de gobernar y la estructura de la Administración Pública. El Estado social administrador de ideología nacional-popular' ${ }^{\prime}$, surgido de la Revolución Mexicana, que había protagonizado la industrialización y modernización del país a lo largo del siglo, había caído exhausto a causa de su déficit de recursos fiscales y políticos. En la década de los ochenta resultó claro al país que era necesario replantear las relaciones entre sociedad y Estado, así como revisar el funcionamiento de la organización estatal, la estructura económica y, en consecuencia, el ámbito y estilo de gestión gubernamental. Más que reordenar la Administración Pública ${ }^{2}$, era impostergable redimensionar y reformar el Estado.

Se ha argumentado que hasta 1982, el régimen político mexicano había hecho descansar su legitimidad y consenso en su capacidad para impulsar el desarrollo económico ${ }^{3}$ y para satisfacer las diversas demandas de los grupos sociales mediante la provisión de bienes y la prestación de servicios (politica de masas). La eficacia social de la acción gubernamental (legitimidad por gestión) fue por décadas el soporte de la legitimidad política. Sin embargo, en 1982, la crisis fiscal del Estado llevó el estilo de gestión gubernamental imperante a su límite. Para resolver a fondo la crisis no fue suficiente, aunque necesaria, la política de ajuste y estabi- lización económica. Por convicción y por fuerza de las circunstancias, el gobierno tuvo que ir más allá. Indujo el cambio estructural de la economía nacional con la apertura comercial y la regionalización económica, hizo refluir la crecida y directa intervención estatal en la economía y redimensionó el tamaño de sus organismos y de la empresa pública, abandonando el agotado modelo del primer desarrollo mexicano. Sobre todo, en respuesta a la insurgencia política de la sociedad, inició el cambio político de la democratización del régimen.

La reforma del Estado mexicano ha sido una empresa colectiva compleja, multidimensional, que no es entendida correctamente si es vista única o unilateralmente como un desmantelamiento o achicamiento del aparato estatal por la presión de tener que sanear las finanzas públicas en bancarrota. El estímulo inmediato para iniciar y acelerar la reforma del Estado mexicano proviene sin duda de su pesado déficit fiscal, pero también del déficit de consenso político que conllevó la crisis fiscal, síntoma y resultado de todo el estilo posrevolucionario de gobernar y administrar. En el fondo, la reforma del Estado es la respuesta a la crisis de toda una economía política, es decir, de un modelo de desarrollo económico y de la red de instituciones y prácticas políticas que lo sustentaban. Por ello, la reforma es, sobre todo, el intento serio y global de armar una nueva economía política para México, un nuevo sistema económico, político y administrativo. La envergadura de la empresa explica asimismo las resistencias, reticencias, impugnaciones y hasta el levantamiento armado de Chiapas en este año. Muchas cosas cambiaban al mismo tiempo y muchos, con buenas 0 
malas razones, se han opuesto al sentido, alcance y velocidad del cambio.

La reforma del Estado mexicano tiene cinco dimensiones o niveles interdependientes y que, sólo por fines de análisis, pueden distinguirse y separarse: a) reformas en el proceso de gobierno y de la Administración Pública, que conllevó primero la reducción del tamaño del aparato estatal (organizaciones, programas, empresas, personal), mediante cancelación, fusión, liquidación y privatizaciones, y que luego comportó cambios en las formas de realizar las funciones económicas y sociales de la rectoría estatal (desregulaciones, servicios públicos concesionados o contratados, focalización de los subsidios, cooperación de gobierno y sociedad en el cumplimiento de la función pública); b) reformas en el régimen político mismo, que se plasman en cambios de las instituciones y procesos electorales (democratización), en nuevas formas de composición de los poderes del Estado, en una más real división de poderes, en un retorno al federalismo, en la incorporación del pluralismo político y en una más activa protección de los derechos humanos; c) reformas en la Constitución Política misma, que rediseñan el ámbito público y privado, el ejercicio del poder y de la libertad ciudadana, y que tienen el propósito de construir la nueva economía política nacional; d) reformas en el modelo de desarrollo, que dan paso a la liberalización, la apertura y la globalización económica y reubican el papel del Estado en el nuevo patrón productivo y distributivo; e) más discutidamente, reformas en la cultura política, en las nuevas ideas y expectativas sobre la función del Estado y el criterio de legitimidad del gobierno, en el asentamiento de los valores y actitudes de la democracia (pluralismo, tolerancia) y en un creciente énfasis en el valor político del Derecho, en leyes generales y autoridades imparciales, en contrapunto a una vieja tradición política de carácter patrimonialista y populista.

En este artículo se busca exponer, tal vez de manera descriptiva más que analítica, un panorama general de las reformas, a partir de la crisis económica y política de 1982 hasta las elecciones de agosto de 1994. Concentraré particularmente la atención en las primeras cuatro dimensiones de la reforma estatal y dividiré el artículo en tres secciones: la reforma económicoadministrativa, la reforma politico-electoral y la reforma constitucional, poniendo respectivamente el énfasis en el proceso de redimensionamiento del Estado, en la democratización del régimen político y en los aspectos cruciales que las reformas constitucionales tienen para el armado de la nueva economía política mexicana.

\section{La reforma económico- administrativa}

Se han elaborado diversas explicaciones sobre el crecimiento de las funciones, organizaciones y empresas del Estado mexicano y suelen ser de dos tipos, socioeconómicas y políticas. Las primeras insisten en la debilidad de la sociedad mexicana de la primera mitad del siglo. Se trata de una sociedad dividida, heterogénea, atrasada, pobre en capital y recursos humanos, incapaz de enfrentar la modernización del país. De aquí, la necesidad de un fuerte poder estatal central para integrar, organizar y desarrollar la sociedad nacional. Las explicaciones políticas marchan por otra dirección y son menos positivas en la apreciación de los motivos del protagonismo gubernamental. Parten de la premisa de la centralización posrevolucionaria del poder que monopolizó la coacción y la iniciativa política y que hizo descansar su legitimidad en su capacidad de ofrecer bienes y servicios a los grupos demandantes, en lugar de la elección ciudadana entre opciones competitivas. El crecimiento del aparato gubernamental es entonces imputable a un sistema político sin contrapesos y pluralidad y a un patrón de gobierno, propenso a la gestión directa de bienes y servicios, para fines de mayor visibilidad de su acción y superior control de los beneficiarios. Al énfasis en la gestión directa pertenece la dilatación de la empresa pública.

Los estudios retrospectivos más importantes señalan tres períodos en el proceso de intervención económica del Estado mexicano: 1925-1946, años dedicados a reactivar y reordenar la actividad económica después de la revolución; 1947-1955, años orientados a promover y sostener el proceso de industrialización; 1956-1982, periodo en que el Estado participa directamente en la producción de bienes y servicios. En los primeros dos tiempos la empresa estatal opera en el campo de la energía, el transporte y los insumos industriales básicos con el propósito de apoyar el proceso de industrialización y a la empresa privada, considerada como el principal actor del desarrollo; en el tercer tiempo, la empresa estatal se extiende desmesuradamente por todas las ramas productivas, hasta llegar a participar en 45 de las 73 ramas económicas entonces existentes.

La razón frecuentemente invocada desde los años sesenta para justificar la intervención del Estado en las actividades de mercado fue la de preservar el empleo y la planta productiva a causa de la ineficiencia económica de ciertas empresas privadas, próximas a la quiebra. Pero, a partir de los años setenta, fue determinante el 


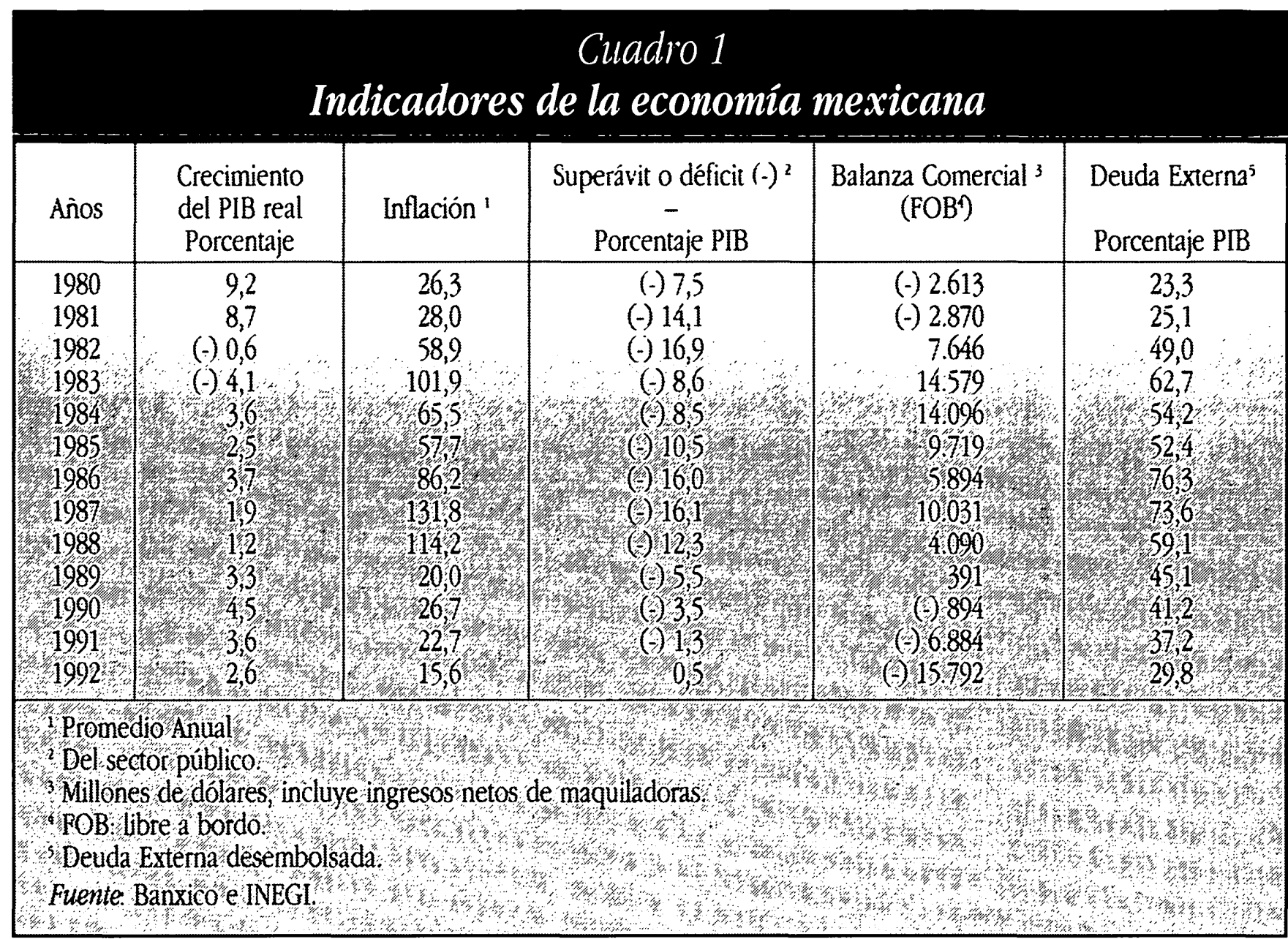

argumento de que la intervención estatal directa en la economía era condición necesaria para reorientar el extraviado desarrollo hacia el bienestar social y la distribución de la riqueza, conforme al ideal nacional-popular de la Revolución Mexicana, el cual se consideraba ajeno a la iniciativa privada capitalista, y a la política de desarrollo estabilizador seguida por el gobierno en las décadas pasadas. Los años setenta se caracterizaron entonces por la concepción explícita del Estado como el agente económico estratégico de la empresa histórica del desarrollo, más determinante que los privados y el mercado. Si se quería seguir hablando de economía mixta, la economía pública tenía la supremacía y la conducción sobre una economía privada, tal vez útil pero sospechosa. En consecuencia, se asentó y divulgó una idea estatista, nacionalista y socializante del desarrollo. Con esta teoríaideología de respaldo el aparato estatal aceleró su dilatación en los setenta.

Mil novecientos ochenta y dos fue el inicio de la crisis del Estado mexicano. Después de tres años de altas tasas de crecimiento económico (tasas históricas de 8 por 100), cuyo motor fueron los ingresos petroleros extraordinarios y el fácil acceso al financiamiento externo ${ }^{s}$, la inflación se disparó, el PIB descendió por primera vez desde los años cincuenta y los salarios reales cayeron en 12 por 100 , al mismo tiempo que las tasas de interés internacionales, aunque con fluctuaciones diversas, se situaron muy por arriba de los niveles que tenían en años anteriores. En consecuencia, el peso mexicano se devaluó 276 por 100 en el período de un año, el déficit del sector público creció alarmantemente a un 17 por 100 del PIB y se fugaron capitales por casi 22 mil millones de dólares (véase cuadro 1).

Las medidas reactivas de nacionalizar la banca privada en 1982 e introducir el control del tipo de cambio empeo-raron la situación macroeconómica y desataron efectos políticos de deslegitimación y repudio al gobierno en sectores sociales fundamentales para la economía y la estabilidad políica (empresarios y clases medias). El cuadro crítico terminó por agudizarse cuando los acreedores externos se negaron a seguir prestando dinero a México, por su insolvencia. El país pasó de ser un importante receptor de ahorro externo a constituirse en un emisor de capitales ${ }^{6}$. 
En diciembre de 1982, el nuevo presidente Miguel de la Madrid reconoció explícitamente la crisis fiscal y administrativa del Estado, a la que hizo frente con un conjunto de iniciativas institucionales y de política, que incluyeron desde reformas constitucionales (a los artículos 25 , 26,28 y 115), presupuestarias y programáticas, hasta la puesta en marcha del primer programa de estabilización económica.

\section{Las reformas constitucionales}

El objetivo de los cambios constitucionales fue adecuar el entramado institucional del país, a la situación crítica del país, que se imputaba a la gran concentración del poder en el gobierno federal, en la presidencia de la República, así como a la amplitud y discrecionalidad de sus decisiones e intervención, sin el balance efectivo de los otros poderes estatales y el control democrático de la sociedad. El cuestionamiento social apuntaba así a la fuerte centralización del poder público, a la ausencia de reglas claras y precisas acerca del ámbito de la intervención estatal en la economía, y a la necesidad de democratización del régimen político. Centralización decisoria, rango desmesurado de intervención estatal y autoritarismo eran para la mayor parte de la opinión pública las causas de la ineficiencia, imprevisión y arbitrariedad gubernamental que habian llevado al país a la crisis.

La respuesta institucional y política del gobierno al enjuiciamiento social fue entonces: a) la reforma municipal (artículo 115), en el marco de la descentralización de la vida nacional (uno de los lemas centrales de la campaña electoral y del gobierno delamadridista); b) la definición clara del ámbito y modo de la rectoria económica del Estado; y, en conexión, c) la idea de planeación democrática (artículo 25, 26, 28) como el modelo y estilo de la gestión pública.

Con la reforma al artículo 115 se buscó reactivar el papel político-administrativo del municipio. Las modificaciones introdujeron la forma de representación política proporcional en los ayuntamientos, con el fin de dar mayor presencia a los partidos políticos de oposición, y buscaron crear las condiciones para el buen funcionamiento del municipio. En términos generales, se redefinió el papel asignado a este orden de gobierno en la estructura del sistema federal mexicano mediante la definición de las fuentes de ingresos municipales, la enumeración explícita de los servicios públicos a su cargo y el reconocimiento de su autonomía reglamentaria ${ }^{7}$.

También se estableció, con los cambios al artículo 26 constitucional, el Sistema Nacional de Planeación Democrática (SNPD) y la obligación de gobernar conforme a un Plan Nacional de Desarrollo (PND) para recobrar el carácter público, socialmente consultado y pactado de la acción del gobierno y fortalecer la planeación como requisito para racionalizar la acción gubernamental entre objetivos, medios y recursos. En el artículo 25 se redefinió el ámbito de intervención del Estado, se reiteró el derecho estatal a la rectoria del desarrollo nacional, su exclusividad en las áreas estratégicas de la actividad económica y su concurrencia con los sectores social y privado en las áreas prioritarias ${ }^{8}$. En contraste, las ramas económicas no estratégicas ni prioritarias para el desarrollo nacional serían dejadas a la acción libre de los sectores privado y social.

El proyecto inicial de De la Madrid no se planteó la cuestión de revisar críticamente la concepción tradicional de un Estado grande, dominante, ni la de un gobierno socialmente activista, que había sido el origen del crecimiento de la intervención estatal y del aparato gubernamental. Sin embargo, las reformas delamadridistas iniciaron el proceso de redefinición de las relaciones entre Estado-sociedad en un momento institucional muy delicado. Por un lado, una sociedad cansada de la gran discreción presidencial en la toma de decisiones colectivas vitales y, por el otro, un gobierno desacreditado dentro y fuera del país. Los cambios constitucionales crearon las condiciones para que después, cuando se reconoció en 1985 la imposibilidad de regresar al primer modelo de desarrollo (endógeno, sustitutivo de importaciones, centrado en el mercado interno) y al patrón de gobierno que le dio su soporte (intervención, gasto masivo, proteccionismo, control, centralización) se diera paso, primero, al redimensionamiento del Estado y, después, a lo que hemos llamado reforma del Estado.

\section{Los programas de ajuste económico}

Ante la crisis de 1982 se formuló el primer plan de estabilización, conocido como Programa Inmediato de Reordenación Económica (PIRE). Se trataba de un programa de corte ortodoxo orientado al control de la demanda agregada, con el objetivo de corto plazo de restablecer la estabilidad de precios. Las medidas del PIRE fueron diseñadas particularmente con el fin de corregir las finanzas públicas: recortes en el gasto público y aumentos de los ingresos mediante una reforma fiscal a fondo y la actualización realista de los precios y tarifas del sector público. Como resultado de las medidas adoptadas se logró que el PIB en 1984 y 1985 creciera 3.6 y 2.5 por 100 , respectivamente, y que la inflación bajara de 101.9 por 100 en 1983 a 57.7 por 100 en 1985 (véase cuadro 1). No obstante la política de ajuste, la economía 


\begin{tabular}{|c|c|c|c|c|c|c|c|c|c|}
\hline Mes & 1984 & 1985 & 1986 & 1987 & 1988 & 1989 & 1990 & 1991 & 1992 \\
\hline 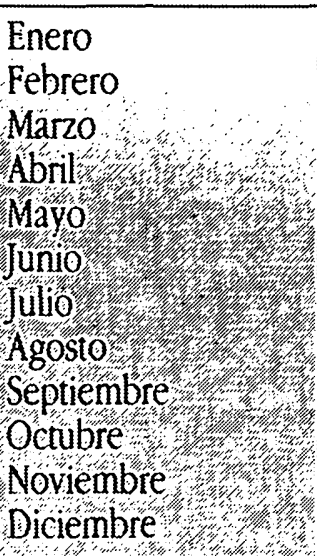 & 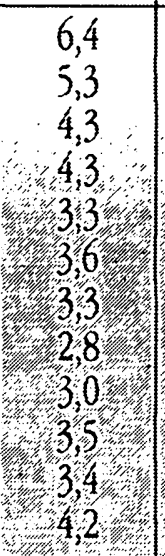 & 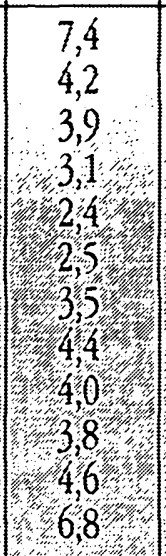 & 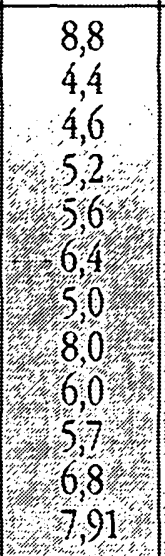 & 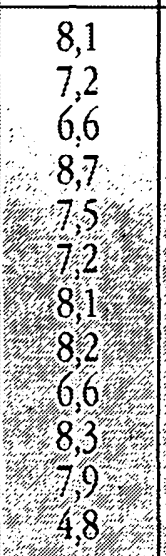 & 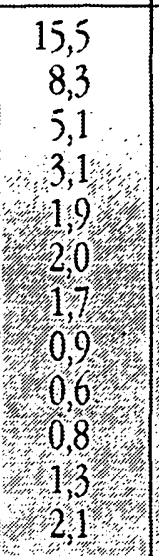 & 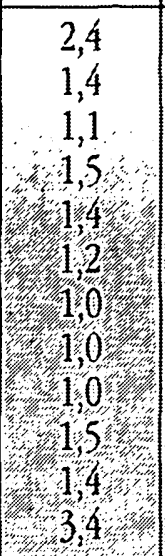 & 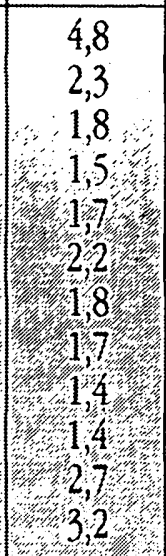 & 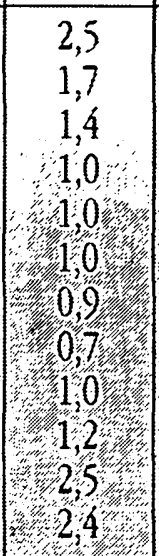 & 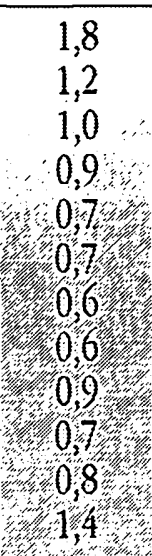 \\
\hline
\end{tabular}

seguía siendo muy vulnerable a los choques externos. En octubre de 1985 , se desplomaron 50 por 100 los precios internacionales del petróleo, que pasaron de veinte a diez dólares por barril y que representaron una fuerte pérdida de ingresos públicos por más de ocho mil millones de dólares, y desordenaron la presupuestación pública. A este choque hay que añadir otro, de origen natural, provocado por los sismos de septiembre de 1985 en la Ciudad de México y en la región central del país, que presionaron aún más el gasto público en las tareas de reconstrucción y agudizaron el malestar social.

Ante lo precario de la situación, el gobierno decidió poner en práctica, en junio de 1986, otro programa ortodoxo de ajuste: el Programa de Aliento y Crecimiento (PAC). El objetivo era buscar el crecimiento de la economía con reducción de la inflación. Con el PAC la actividad económica creció hasta el tercer trimestre de 1987; sin embargo, la tasa promedio de inflación mensual en esos meses no disminuyó y se ubicó entre 6.6 por 100 y 8.2 por 100 (véase cuadro 2).

Durante los últimos meses de 1987, una grave crisis financiera (caída de la Bolsa Mexicana de Valores) interrumpió el proceso de recuperación de la economía. El ambiente de incertidumbre provocado por esa crisis y la inercia inflacionaria dieron lugar a una corta pero intensa fuga de capitales que culminó con la devaluación de noviembre de 1987, hecho que colocó al país en el camino de la hiperinflación ${ }^{9}$. Ante esto, el movimiento obrero organizado demandó un aumento salarial de emergencia del 46 por 100 y que, de no otorgarse, provocaría una huelga general. Entre 1982 y 1987, el salario mínimo general había sufrido una reducción del 44.6 por 100 , en términos reales, mientras que los salarios contractuales, incluyendo prestaciones, descendieron un 40.5 por $100^{10}$.

Algunos meses atrás, a raíz de la instrumentación de programas heterodoxos en Argentina, Brasil e Israel, ya se hablaba sobre la viabilidad de uno similar en México. Las autoridades mexicanas se resistieron inteligentemente a ponerlo en marcha antes de contar con los prerrequisitos que aseguraran algún éxito. Se consideraba indispensable contar con un superávit primario elevado "y tener suficientes reservas internacionales para poder hacer frente, temporalmente, a posibles choques externos y permitir las importaciones necesarias para el funcionamiento del aparato productivo. Paralelamente, se requería corregir los rezagos existentes en los precios controlados y tarifas públicas para evitar posibles presiones de aumentos drásticos, una vez iniciado el plan ${ }^{12}$.

Para enfrentar el problema de las expectativas inflacionarias inerciales se reconoció la necesidad de concertar con los principales agentes de la economía el programa de estabilización, con el fin de que la desconfianza y la inseguridad no se tradujeran en recesión y desempleo ${ }^{13}$. La exitosa concertación entre gobierno, capital y trabajo se convirtió en uno de los mecanismos más eficientes para alcanzar la estabilización económica y, luego, para el cambio estructural de la economía mexicana: el paso a 
una economía abierta, competitiva y globalizada, con funciones de regulación y promoción por parte del Estado.

El presidente Miguel de la Madrid convocó a los representantes de los sectores obrero, campesino y empresarial el 15 de diciembre de 1987 para firmar el Pacto de Solidaridad Económica (PSE), el cual estuvo vigente hasta diciembre de 1988. Las principales medidas del Pacto se pueden clasificar en ortodoxas y heterodoxas ${ }^{14}$. Entre las primeras se encuentran las relativas a la política fiscal, monetaria y de deuda pública; entre las segundas están la política cambiaria, de precios y salarios ${ }^{15}$. Asimismo, se continuó con los cambios estructurales, el redimensionamiento del sector público y la apertura comercial. Se trataba de un enfoque a dos manos: 1) control de la demanda y 2) concertación por el lado de la oferta.

Con el PSE aumentaron los ingresos públicos mediante la ampliación de la base gravable, la simplificación de las disposiciones fiscales, la puesta en marcha de programas más rigurosos para combatir la evasión y elusión fiscal, la reducción de tasas impositivas y la eliminación de bases especiales de tributación ${ }^{16}$. Por otro lado, se continuó con la disminución del gasto público, principalmente del gasto corriente y de las transferencias a las empresas estatales ${ }^{17}$.

Los doce meses que duró el PSE fueron decisivos para que las autoridades lograran convencer a la sociedad de que las medidas fiscales y comerciales tendrían resultados inmediatos y permanentes. En efecto, la inflación se redujo drásticamente en más de cien puntos porcentuales y pasó de una tasa anualizada, en diciembre de 1987, de 159 por 100 a una cercana a 52 por 100 a finales de 1988. Las cifras del PIB muestran que la economía tuvo un crecimiento modesto durante este período, ligeramente superior al 1 por 100 en 1988, respecto al año anterior (véase el cuadro 1). La inflación se logró reducir sin frenar drásticamente el ritmo de la actividad económica.

Con la llegada al gobierno del presidente Carlos Salinas de Gortari, sobre la base de lo logrado, se aceleró el paso para lograr de una vez por todas la recuperación económica con estabilidad de precios. Para ello, se concertó un nuevo pacto, el Pacto para la Estabilidad y el Crecimiento Económico (PECE), que entró en vigor en enero de $1989^{18}$. En esencia, el nuevo pacto buscaba dar continuidad y acelerar los avances del programa anterior ${ }^{19}$.

Es importante tener presente que el programa de estabilización no hubiera tenido éxito si no se disminuían las altas transferencias de recursos al exterior. Sin lugar a dudas, la viabilidad macroeconómica del programa estaba estrechamente vinculada con el monto ${ }^{20}$ y el horizonte de transferencias. Durante el gobierno de Miguel de la Madrid se llevaron a cabo dos importantes acciones. La primera de ellas estuvo encaminada a la reducción de la deuda; para ello el gobierno mexicano presentó a sus acreedores bancarios una propuesta para intercambiar, con descuento y mediante subasta, su cartera de deuda por bonos nuevos. La segunda fue la relacionada con el refinanciamiento de la deuda a cargo del sector privado y registrada en el Fideicomiso para Cobertura de Riesgo Cambiario (FICORCA).

No obstante, estas medidas fueron insuficientes. Por ello, el presidente Salinas emprendió con rapidez, durante los primeros meses de su gobierno, una nueva renegociación de la deuda externa. La estrategia de negociación se planteó en dos etapas: la primera con los organismos financieros internacionales y con el Club de París; y la segunda, con la banca comercial. Con los primeros se pretendia tanto reducir las transferencias netas de recursos como contar con su apoyo político para defender la tesis de que para volver a crecer se requería disminuir la carga de la deuda externa. En cambio, la estrategia con la banca comercial se orientó a abatir las transferencias de recursos a través de la reducción del valor nominal del saldo de la deuda o de las tasas de interés que se pagaban sobre la misma ${ }^{21}$. De acuerdo con cifras oficiales, el monto de la deuda sujeta a renegociación fue de más de 48 mil millones de dólares, es decir, poco más de la mitad de la deuda total a fines de $1989^{22}$. Las transferencias netas de recursos como porcentaje del PIB pasaron de 6.1 en 1984 a (-) 5.8 en 1991 (véase cuadro 3).

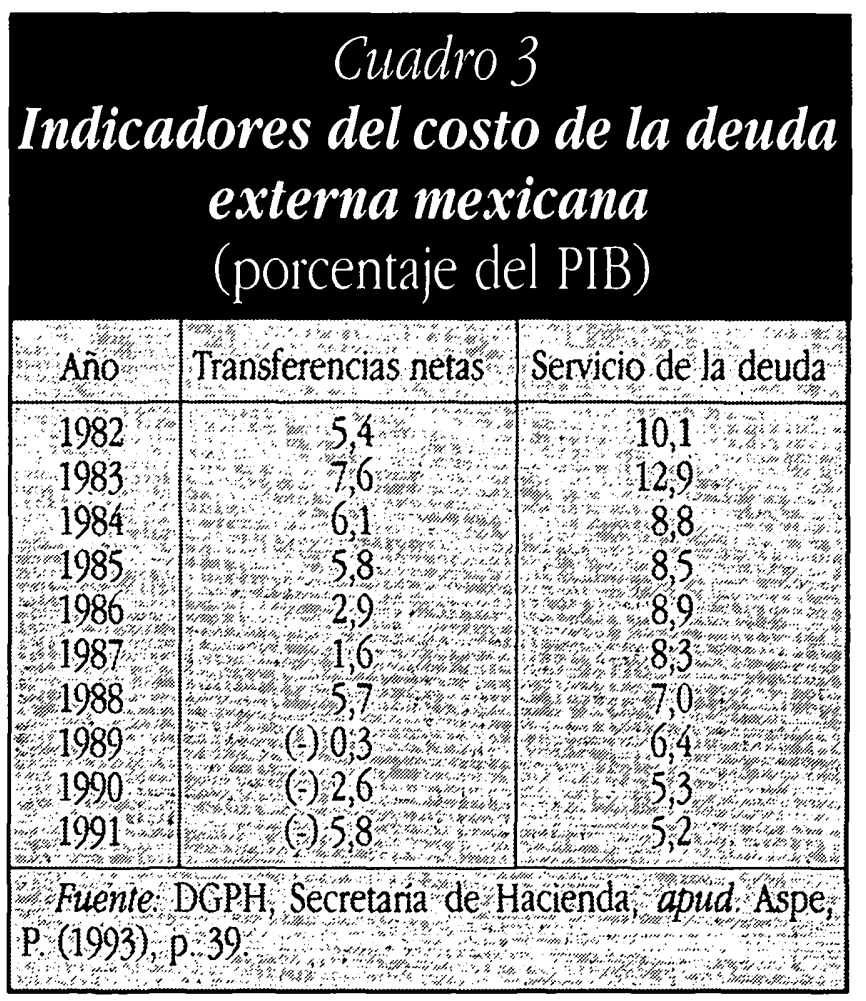




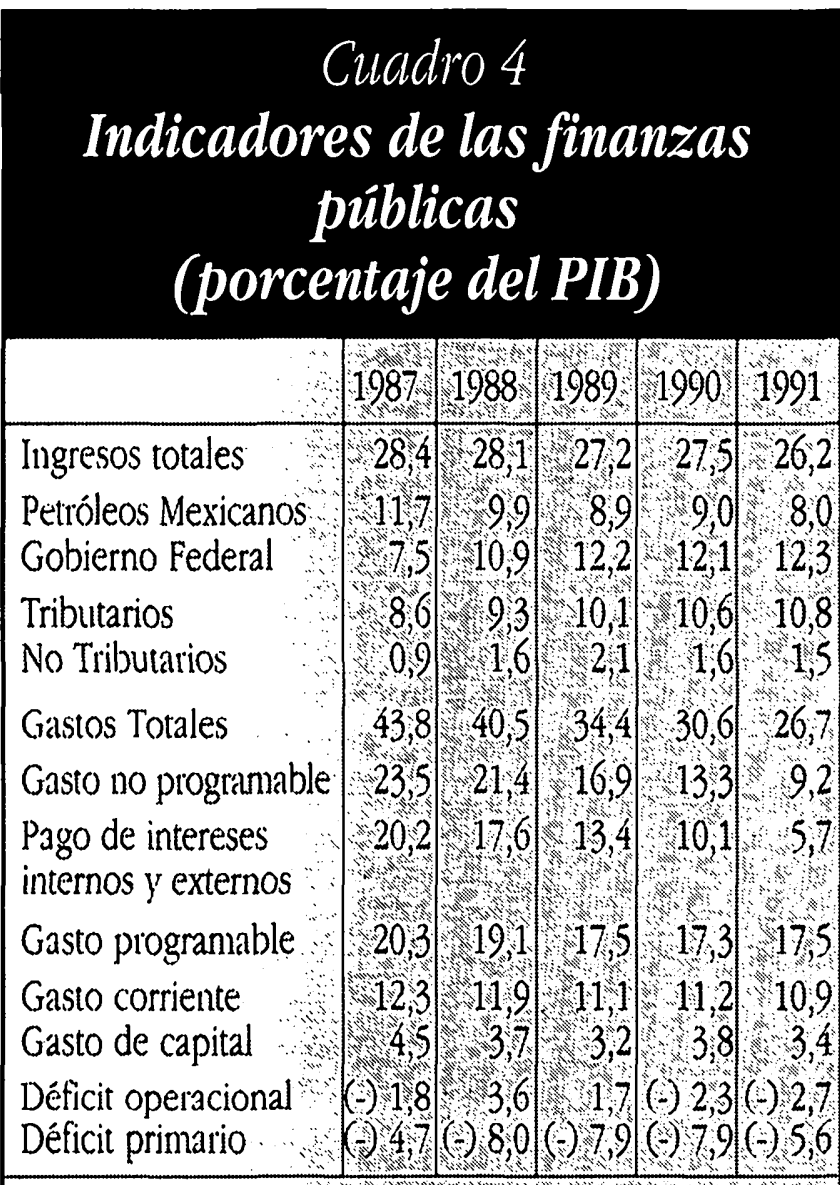

Fuente: DGHP-DGPI Secretaría de Hacienda Las cifras para 1991 se tomaron de Criterios, Presidencia de la República. El cuadro no incluye el sector paraestatal no controlado. El gasto programable incluye el gasto comiente, el gasto de capital y transferencias a enpresas no controladas.

Para medir el impacto de los programas de estabilización (PSE y PECE) basta ver el efecto global de las iniciativas de ingreso y gasto que se resume en el cuadro 4 . Lo que resalta por su importancia es el incremento del superávit primario de casi 3.3 puntos del PIB durante el primer año del PSE.

Cabe mencionar que en el marco del PECE, como complemento a los cambios en la política de gasto, se puso especial interés en el apoyo a la población de más bajos ingresos. En el Plan Nacional de Desarrollo 19881994, el Programa Nacional de Solidaridad (PRONASOL) se consideró el instrumento del gobierno para combatir la pobreza extrema. Con el redimensionamiento del aparato estatal y la consecuente reducción del gasto público, el combate a la pobreza extrema se convirtió en una de las mayores prioridades gubernamentales. Uno de los fenómenos que acompañaron a la crisis económica de 1982 fue el crecimiento de los sectores más pobres y marginados: comunidades indígenas, campesinos y grupos populares urbanos ${ }^{23}$.

PRONASOL está dirigido a esos grupos sociales y se propone elevar su nivel de vida. Todas las acciones de este programa se sustentan en la participación de las comunidades con el gobierno. Esa participación significa que las comunidades aportan mano de obra y los recursos a su alcance, y el gobierno, el resto de los recursos necesarios para el desarrollo del programa que elige la comunidad. Esta última debe organizarse en un Comité de Solidaridad para dirigir el desarrollo del programa que se escogió. El gobierno federal descentraliza la ejecución de los programas por él diseñados a los gobiernos estatales y municipales que se encargan de dar una respuesta a los demandantes.

Se ha considerado que teóricamente las políticas sociales de PRONASOL pueden tener dos tipos de efectos en el seno mismo de la sociedad: primero, efectos distributivos de la riqueza ${ }^{24} \mathrm{y}$, segundo, efectos socializadores en un paso de la comunidad tradicional a la sociedad moderna ${ }^{25}$. En el primer grupo de efectos, se afirma que las políticas públicas que se ponen en práctica a través de PRONASOL facilitan la producción y el acceso a bienes y servicios públicos, ampliando los beneficios del gasto social; además, como el gasto en este tipo de políticas es una inversión con rendimientos a largo plazo, se produce un avance hacia condiciones más adecuadas en la generación de proyectos productivos autofinanciables que permiten un alejamiento efectivo de las condiciones de desigualdad y pobreza. El segundo tipo de efectos estimula la modernización global en México. PRONASOL se puede apreciar como un medio que comporta una dimensión inductora de socialización política moderna: individuos que aprenden a resolver sus problemas particulares en la medida en que contribuyen a resolver los problemas del conjunto.

PRONASOL ha sido un programa nacional de enormes dimensiones. Aunque ha sido muy criticado como un simple programa con fines clientelares que busca aumentar los votos del partido oficial. Sus efectos tangibles muestran que la demanda por sus beneficios y el involucramiento de la sociedad han ido en aumento. De 1989 a 1993, la población beneficiada por los programas de PRONASOL se ha incrementado y se espera que estas cifras crezcan aún más, en la medida y al ritmo que crece la inversión gubernamental que se destina a sus programas. Como vemos en la gráfica siguiente, la inversión federal en los programas ha sido creciente desde 1989.

Así, la política de gasto gubernamental indiferenciado que se originó en una política populista de masas, se 


\section{Inversión Federal en PRONASOL y Desarrollo Regional \\ (Millones de nuevos pesos)}

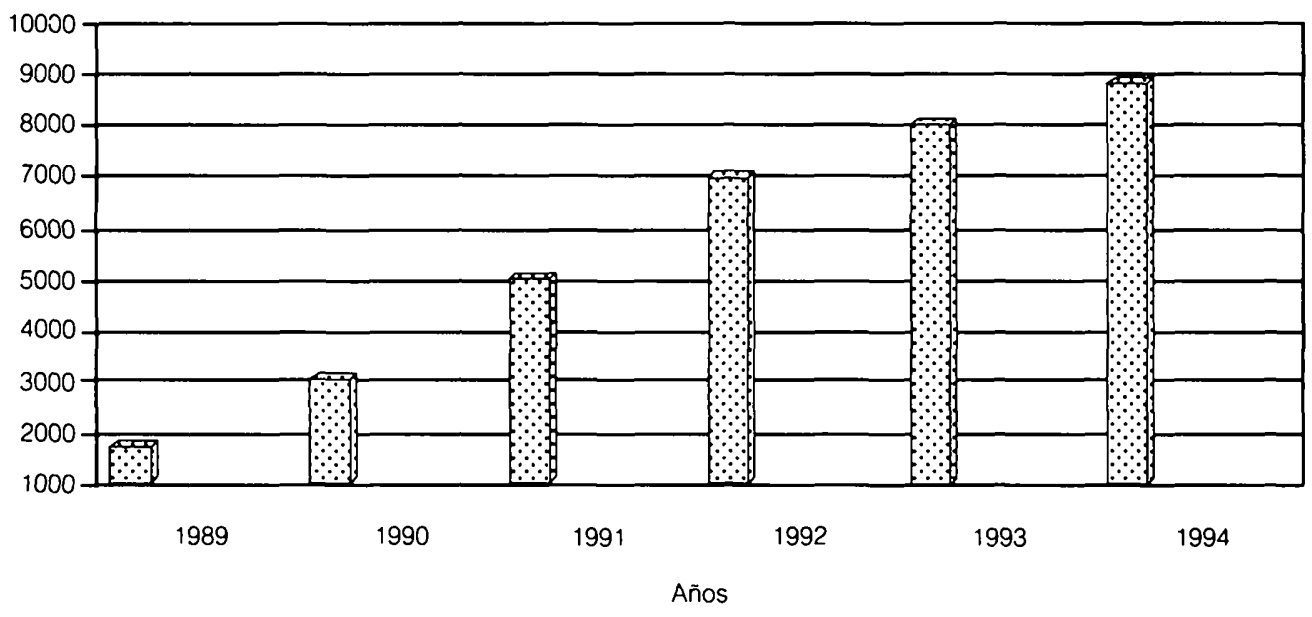

Nota: El dato para 1993 se obtuvo del cierre estimado al 1 de noviembre de ese año, y el de 1994 es de la inversión programada.

Fuentes: Cuenta de la Hacienda Pública Federal, 1989-1992; Carlos Salinas de Gortari, Quinto Informe de Gobierno, 1993 y Presupuesto de Egresos de la Federación, 1994.

cambió por una novedosa política de gasto focalizado, dirigido a quienes necesitan realmente esos subsidios y están dispuestos a participar en la puesta en práctica de los programas.

\section{La nueva estrategia económica: el proceso de desincorporación y la apertura comercial}

El modelo del primer desarrollo económico mexicano trajo necesariamente consigo la participación directa del Estado en la creación de infraestructura, la producción de bienes y la prestación de servicios. No había otra estrategia posible, dada la debilidad de los recursos privados nacionales frente a la ingente empresa colectiva de industrializar y modernizar la economía mexicana con un sentido social. Sin embargo, ya en los años sesenta, fueron notorios los límites y cuellos de botella que enfrentaba la economía mexicana para seguir adelante (pobreza de ahorro interno y de reinversión, obsolescencia y dependencia tecnológica, estrechez del mercado interno, desigual distribución de la riqueza, ...) y, sobre todo, para responder a las nuevas demandas sociales de la población mexicana, surgidas en la primera fase de la modernización. La expresión pública de la rigidez económica y política cobró forma en intensos movimientos sociales a lo largo de los años sesenta, que alcanzaron su clímax en el movimiento estudiantilmagisterial del 68 .

La respuesta gubernamental fue una lectura errónea y parcial de la nueva circunstancia. En lugar de liberalizar y democratizar la política, la respuesta consistió en incrementar la capacidad estatal para proveer con mayores bienes y servicios a los demandantes descontentos, como si se tratara de grupos de interés más agresivos. Para ello se requería que el Estado tuviera una mayor incidencia en la velocidad y rumbo del desarrollo. Se consideró entonces necesaria la intervención estatal directa en la economía con la tesis del desarrollo compartido (presidente L. Echeverría, 1970-1976), en un ambiente intelectual y político de simpatía mayoritaria con esta tesis. En efecto, los años setenta mexicanos fueron años de convicciones y proyectos socializantes o socialistas estrictos. Fue así que el Estado asumió plenamente el papel de agente económico estratégico del desarrollo, por encima del sector privado y del mercado. El indicador más sobresaliente del crecimiento del aparato estatal de aquellos años es, indudablemente, el crecimiento acelerado de la empresa estatal, de programas y organismos gubernamentales y del número de empleados públicos. Así, mientras que en 1970 había 491 empresas públicas y 700 mil empleados del gobierno 


\section{Evolución anual del sector paraestatal}

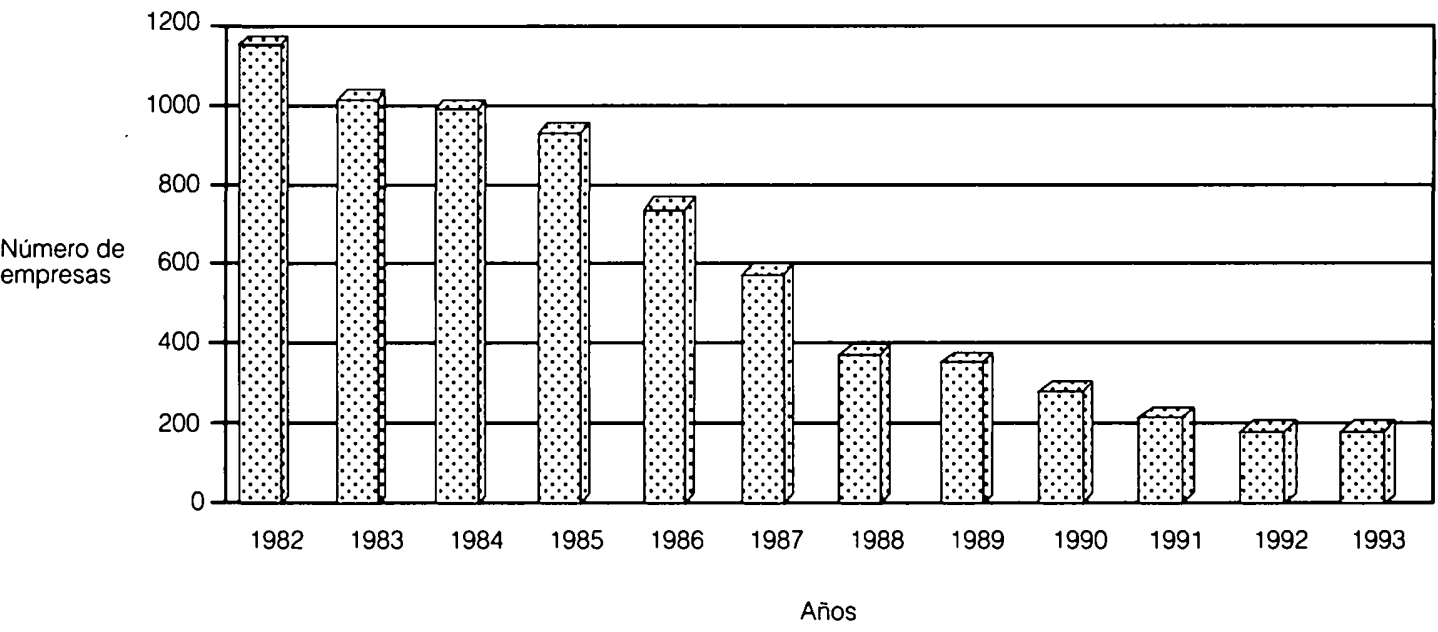

Fuente: Unidad de Desincorporación, SHCP.

o menos rentables y operaban en mercados relativamente competitivos. Su traslado no requería cambios en leyes o reglamentos; la valuación de sus activos era sencilla y la adquisición no necesitaba grandes capitales. Más aún, alrededor de la mitad de las empresas vendidas incorporaban ya un porcentaje significativo de capital privado. Se trataba de hoteles y restaurantes, fábricas de textiles, autopartes, alimentos, bebidas, tabaco y petroquímica secundaria. La obviedad de su innecesario carácter estatal despertó poca oposición. Las primeras privatizaciones fueron además un buen proceso de aprendizaje para la segunda etapa de las empresas públicas de gran tamaño, con mayor peso económico e importancia política y, por ende, con superior complejidad en su proceso de desincorporación ${ }^{28}$.

Como complemento de las medidas anteriores y en el marco del PSE, en enero de 1988, el gobierno firmó el Acuerdo de Austeridad que, entre otros aspectos, incluyó la reducción del gasto corriente, fijándose como meta un recorte del 30 por 100 en relación con el nivel de· 1987. Adicionalmente se eliminaron más de 13 mil puestos de personal público de confianza ${ }^{29}$ y se inició un programa de retiro voluntario para los empleados del sector público. También, a finales de 1987 se habían autorizado incrementos a los precios de la gasolina, el petróleo y el gas ( 85 por 100 ), la electricidad ( 84 por 100 ), el servicio telefónico (85 por 100 en llamadas locales y 55 por 100 en las internacionales), el transporte aéreo (20 por 100), ferrocarriles (17 por 100), el transporte urbano, así como en el azúcar (81 por 100) y los fertilizantes (71 por 100) ${ }^{30}$.

Otra de las medidas claves para la reforma del Estado mexicano fue la desregulación económica y la apertura comercial. En 1985, durante el gobierno de Miguel De la Madrid, México suprimió unilateralmente los permisos de importación sobre casi el 80 por 100 de las fracciones arancelarias sujetas a restricciones cuantitativas (véase el cuadro 6) y, en junio de 1986, el país ingresó en el GATT.

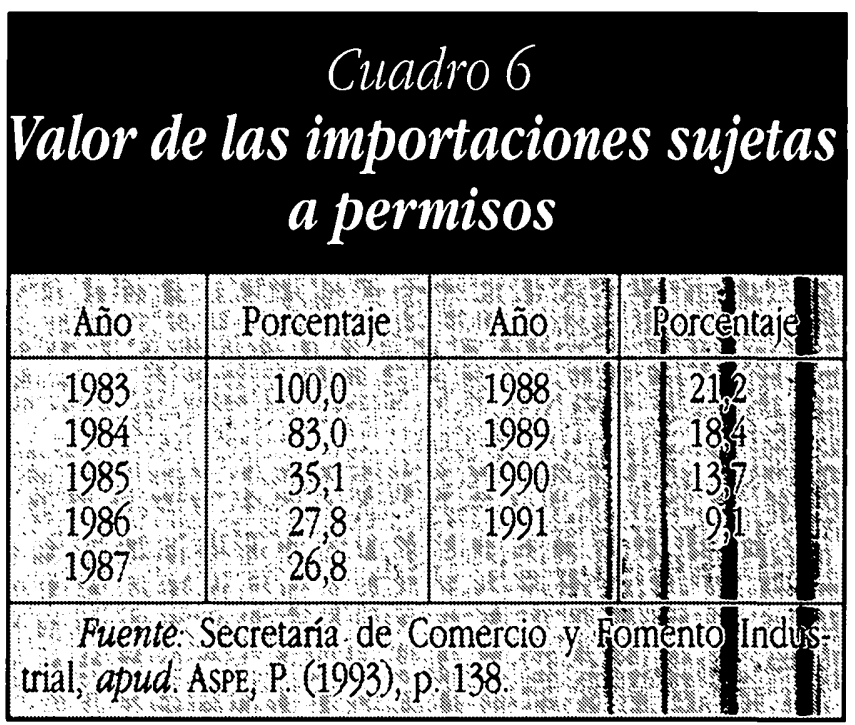


Tiempo después, durante el PSE, se consideró que la competencia externa contribuiría al esfuerzo de reducir la inflación ${ }^{31}$, bajando el precio de los insumos y productos directos al consumidor.

Por otro lado, más allá de las privatizaciones y la apertura comercial, desde 1988, la Secretaría de Comercio y Fomento Industrial fue la encargada de llevar a cabo simultáneamente el Programa de Desregulación Económica, el cual tenía como objetivo eliminar y renovar una enorme cantidad de regulación obsoleta e innecesaria que afectaba negativamente la productividad y la competitividad de algunas actividades económicas ${ }^{32}$. Los cambios más profundos se dieron en los sectores financiero y automotriz, en las telecomunicaciones y en el transporte. La Ley de Competencias y la Ley de Protección al Consumidor son instrumentos recientes que han permitido crear las condiciones microeconómicas adecuadas para el incremento de la eficiencia y la reducción de costos en todos los mercados.

Durante el gobierno del presidente Carlos Salinas de Gortari se continuó con el proceso de desincorporación y el de apertura comercial y liberalización económica. La novedad de este gobierno reside en haber llevado de manera clara el proceso de redimensionamiento a su concepto político-institucional. No se buscaba simplemente sanear las finanzas públicas; no era sólo un programa de ajuste. Se trataba de poner fin al Estado propietario. En este sentido, la desincorporación de la empresa pública fue constitutiva de la nueva manera de concebir las funciones, ámbitos y modos de la intervención del Estado.

Lo que en De la Madrid era adelgazamiento-redimensionamiento del Estado y en el primer Salinas modernización del Estado se convirtió, un año después de su presidencia, en la empresa de la reforma del Estado ${ }^{33}$. La tesis de la reforma es clara:

El punto crucial es: las razones de la desincorporación no son un mero problema financiero ... no se trata de razones de eficiencia de las empresas o los empresarios públicos ... La tesis es de política general: que el Estado cumpla sus responsabilidades constitucionales y sus compromisos sociales fundamentales (Salinas de Gortari.)

Esta tesis se basa en la evaluación de la actuación histórica del Estado desde (la interpretación de) los valores fundamentales de la Revolución Mexicana y/o de la Constitución Política de $1917^{34}$. El Estado a evaluar es el Estado grande, propietario y empresario del pasado inmediato. $Y$ la evaluación le resulta adversa porque, a la luz de la
Revolución, la Constitución incumplió funciones básicas. Sobre todo, porque abandonó su función social: "un Estado más propietario no es hoy un Estado más justo"; "el Estado se extendía mientras el bienestar del pueblo se venía abajo", "era inaceptable un Estado con tantas propiedades frente a un pueblo con tantas necesidades" (Salinas de Gortari).

Hay dos planos en el argumento, uno factual y otro valorativo. El factual (o pragmático, como algunos suelen decir) sigue criterios de eficacia y eficiencia en el cumplimiento de las funciones y ofrece pruebas de que la extensión del aparato gubernamental consumió y distrajo recursos, burocratizó programas, operó desordenadamente, por ende, incumplió sus funciones sociales y, en consecuencia, desatendió la función de garantizar la soberanía (desplazamiento discursivo de la justicia social a la soberanía nacional) y las demás funciones constitucionales. El plano valorativo (o ideológico-político) es más definitorio y sigue criterios de lo que debe ser y hacer el Estado. En esta perspectiva, se afirma categóricamente que el Estado debe hacerse cargo de la función social y que el Estado intervencionista propietario dejó de ser valorativamente la idea de "más Estado con menos justicia". Salinas resume y jerarquiza los dos planos de la evaluación:

El alejamiento del reclamo social se dio no sólo porque las crecientes empresas paraestatales acapararon los recursos financieros, sino porque distrajeron la atención política del gobierno. En los hechos, el Estado se ocupó más en administrar sus propiedades que en atender las necesidades sociales apremiantes (Salinas de Gortari).

Conceptualizada de esta manera, la reforma del Estado no es de ningún modo una ruptura de la tradición institucional e ideológica, ni tampoco una simple reforma administrativa o de gestión pública. Es, en cambio, "volver al Estado que se planteó originalmente la Revolución Mexicana [...] volver al espíritu original de la Constitución de 1917" a sus funciones sociales y nacionalistas. Lo realmente esencial de la reforma son las funciones no el tamaño del Estado, los fines no los medios. Revolución y Constitución "definieron propósitos y no instrumentos rígidos". Por consiguiente, "la desincorporación de empresas públicas no estratégicas responde hoy a un principio de fidelidad con el carácter social y nacionalista del Estado" (Salinas de Gortari). La privatización no contradice sino posibilita hoy la conducción del desarrollo, la rectoría estatal. La privatización no es la eutanasia del 
Estado rector ni la abdicación de sus funciones históricas, sino la necesaria estrategia práctica para devolver el Estado a sus funciones sociales y nacionales básicas. Libera recursos para enfrentar los problemas sociales y configura "grandes consorcios que puedan enfrentar a las grandes transnacionales". La función social, ideológicamente articulada con la función de la soberanía e identidad nacional - la ideología tradicional del "nacionalismo revolucionario", del "nacionalismo popular"-, es tan intensamente prioritaria que:

El punto central en la reforma del Estado es resolver, a favor del pueblo, el dilema entre propiedad que atender o justicia que dispensar; entre un Estado más propietario o un Estado más justo (Salinas de Gortari).

Con este argumento de fondo, se aceleró el proceso de desincorporación y se realizó con éxito la venta de grandes empresas como las dos principales líneas áreas nacionales (Mexicana de Aviación y Aeroméxico), una de las más grandes minas de cobre en el mundo (Compañía Minera de Cananea), la compañía telefónica nacional (Teléfonos de México) y la totalidad de los bancos comerciales. Al 31 de diciembre de 1993 el total de las entidades paraestatales es de 258,210 vigentes y 48 en proceso de desincorporación. De las entidades vigentes 70 son empresas, 38 son bancos de desarrollo y fideicomisos de fomento y 102 son entidades de servicio institucional ${ }^{35}$.

Por el monto de los recursos y el inteligente procedimiento seguido, el caso de Teléfonos de México (Telmex) merece un comentario adicional ${ }^{36}$. El proceso de venta requirió que se tomaran tres tipos de medidas: a) administrativas, financieras y fiscales: transferencia de Telmex de la Secretaría de Comunicaciones y Transportes a la Secretaría de Hacienda y Crédito Público, ajuste de tarifas, recompra de 629 millones de dólares de su propia deuda, venta de cuentas por cobrar de 590 millones de dólares y emisión de bonos por 150 millones de dólares, nuevo contrato colectivo de trabajo, homogeneización de su categoría fiscal ${ }^{37}$; b) medidas legales: modificación del título de concesión, un nuevo marco regulatorio de telecomunicaciones para crear condiciones de mayor competencia en la industria, un programa obligatorio de crecimiento, investigación y desarrollo tecnológico, calidad del servicio; c) mecanismos de ingeniería financiera para optimizar los ingresos de la venta de la compañía, facilitar la transacción y garantizar el control administrativo por parte de los mexicanos ${ }^{38}$. El 13 de diciembre de 1990 se firmó el contrato de compra-venta con el grupo ganador de la subasta de las acciones "AA" con un pago de 1.757 .6 millones de dólares estadounidenses. En mayo el gobierno colocó en veinte países el 50 por 100 del total de acciones "L" de su propiedad, recibiendo ingresos netos de 2.166 .6 millones de dólares. El fuerte sindicato de telefonistas obtuvo un 4.4 por 100 del capital social de la empresa. El gobierno ha reducido su propiedad en Telmex de 56 por 100 a un 11 por 100 y ha transferido el control y la operación de la empresa al sector privado.

En cuanto a la apertura comercial, el gobierno salinista ha fortalecido las relaciones con los principales socios comerciales. El 11 de junio de 1990, los presidentes Salinas y Bush dieron instrucciones para iniciar los trabajos relacionados con un Tratado de libre comercio. En los meses siguientes Canadá se sumó al proceso. En un primer momento se pensó que la firma del Tratado podría realizarse en el mes de febrero de 1993. Sin embargo, el cambio de Administración norteamericana (el triunfo de los demócratas y la llegada del presidente Bill Clinton a la Casa Blanca) en adición a la oposición de los representantes de los sectores agrario y laboral y de los demócratas más proteccionistas abrieron un compás de espera que no habría de concluir sino hasta el mes de noviembre de 1993. Actualmente, el Tratado entre estos tres países es una realidad e integra la zona de libre comercio más grande del mundo. Al mismo tiempo, México ha estado negociando Tratados de libre comercio con otros socios comerciales como son Chile, Bolivia, Costa Rica, Panamá, Venezuela y Colombia.

\section{La reforma político- electoral}

El desastre económico en México a principios de la década de los años ochenta no se consideró por la sociedad más atenta e ilustrada como el resultado únicamente de un mal diseño de las políticas económicas o de una defectuosa gestión pública. Su raíz estaba más allá del desempeño administrativo; se encontraba en el exagerado protagonismo y discrecionalidad del gobierno federal, en la inactiva división de poderes, en un poder central sin el contrapeso de los gobiernos locales, en un partido dominante sin la presión de la competencia abierta y, en el fondo, en la inconclusa democratización del régimen. La cuestión de la democracia sin adjetivos o de la transición democrática irrumpió entonces con toda su fuerza en la década de los ochenta, estableciéndose explícita o implícitamente en la opinión pública una correlación entre autoritarismo y crisis, entre autoritarismo y estancamiento del desarrollo nacional. La insurgencia política de la sociedad obligó a plantear una serie de cambios profundos en el sistema político y electoral. 
La necesaria política de ajuste y redimensionamiento iniciada por el presidente Miguel de la Madrid para enfrentar la crisis no era suficiente. Aunque el gobierno de la crisis quería y parecía reducir el asunto a pura gestión pública (saneamiento de las finanzas públicas, reordenamiento y planificación de la acción gubernamental, descentralización de la gestión), gran parte de la sociedad entendía la solución de la crisis como una cuestión política y no sólo de políticas. Tampoco era suficiente y radical la propuesta de planeación democrática, en el sentido de que el proyecto de gobierno iba a estar sujeto a consulta y concertación con los sectores sociales más importantes. Para evitar desastres por causa de decisiones públicas autoritarias, lo decisivo eran elecciones democráticas en una contienda legal y equitativa entre diversos partidos políticos, así como el control democrático de los gobernantes. De hecho, quedó muy claro, casi desde el comienzo de la presidencia de De La Madrid, que el ajuste económico y el cambio estructural de la economia que trajo consigo, contenían una dimensión política inevitable. La reforma financiera y administrativa pública desataban efectos directa y centralmente políticos.

En efecto, los ajustes en las finanzas públicas tenían impactos muy poderosos en el sistema político. El cambio en el estilo de gobierno y administración, al que obligó la crisis de los años ochenta, alteraba el estilo de hacer política, la manera como los grupos y los líderes acostumbraban a representar, agregar y tratar sus intereses y demandas, la manera tradicional de resolver los conflictos y de concertar los consensos entre las organizaciones rivales y el gobierno.

El reflujo de la intervención estatal -menos gasto, cancelación de programas, liquidación y venta de empresas públicas, etc.- llevó naturalmente a alterar el patrón de gestión gubernamental. No responder (o responder por debajo de las expectativas) a demandas tradicionales, diseñar otras políticas para atender las demandas (sustituir con medios de regulación y promoción la estrategia tradicional de gasto, propiedad y gestión directa en el tratamiento de muchos asuntos), no asumir como asuntos públicos de competencia gubernamental y de atención prioritaria ciertas reivindicaciones inerciales de las organizaciones, ser sordos a ciertos discursos ideológicos, etc., eran cambios profundos en el patrón de gestión pública. Y ocasionaron, en consecuencia, cambios rápidos y profundos en la interlocución/negociación entre sociedad y Estado, entre las organizaciones sociales y los poderes del Estado: en la política misma.

Organizaciones sociales y liderazgos, acostumbrados a arrancar prestaciones y beneficios del gobierno a cambio de contener el conflicto, garantizar la paz social y dar apoyo (una política de presión y, en casos extremos, hasta de chantaje), empezaron a perder fuerza apenas el gobierno no disponía de recursos para repartir y obligaba a buscar otras alternativas más racionales de planteamiento y solución de los problemas sociales. Los grupos cuya fuerza dependía enteramente del patrón tradicional de gobierno se debilitaron y avanzaron grupos otrora heterodoxos y hostigados (movimientos sociales independientes, asociaciones cívicas, grupos autónomos, coordinadoras populares, organizaciones no gubernamentales, partidos políticos de oposición...). Los tradicionales compulsivos organismos empresariales, obreros, campesinos padecieron crisis de representatividad al tiempo que emergían nuevas asociaciones con comportamientos, liderazgos y discursos alternativos. Aparecen fracturas en la élite política (Corriente Democrática del Partido Revolucionario Institucional en el año de 1986, es ilustrativa), se separan grupos de aliados, se escinden las organizaciones, aumenta la oposición al gobierno en la opinión pública y, muy promisoriamente, para el orden político futuro, se expande la pluralidad y autonomía política: hacia un sistema de partidos.

\section{Antecedentes de las reformas electorales salinistas}

Aunque la última década ha sido el despertar de la política democrática, los procesos de democratización del régimen tienen una larga historia, aunque pausada y gradual. La primera gran reforma político-electoral ocurrió en 1977-1978, en el gobierno de López Portillo, con el fin de dar cabida y representatividad en el sistema político a nuevas voces y fuerzas que no podian ser ya contenidas en el perímetro del partido dominante, el Partido Revolucionario Institucional (PRI). Particularmente buscó incorporar a la vida política institucional a los movimientos de izquierda que, en los años setenta, por razones revolucionarias o por estrechez de los canales de representación y lucha política, habían terminado en focos guerrilleros rurales y urbanos o en una oposición política tan frontal como sin salida.

En 1977-1978, las reformas constitucionales, así como las posteriores reformas a la ley electoral, iniciaron los cambios hacia la liberalización del sistema político. En esa fecha, se dio plena vigencia y se puso atención en el sistema de representación proporcional en el Congreso; se estableció el sistema de autocalificación por parte de la Cámara de Diputados, bajo el principio de proteger su autonomía frente a otros poderes; y se aprobó el recurso de reclamación ante la Suprema Corte de Justicia que, posteriormente, en la reforma de 1986 , sería eliminado y 
sustituido por tribunales electorales; se crearon asimismo mecanismos que disminuyeron los requisitos de representatividad y facilitaron el registro a los partidos políticos de oposición.

En 1986, en la segunda mitad del gobierno de De la Madrid, se lleva a cabo otra gran reforma electoral, ahora preocupada por dos conjuntos de temas, muy vivos entre los partidos: la representación proporcional de las fuerzas en el Congreso y la composición y autonomía de los órganos electorales. La nueva reforma entrará inmediata0 mente en crisis en las discutidas elecciones de 1988, que I llevan a la presidencia de la República a Salinas de Gortari, al no poder resolver el problema de la imparcialidad y confiabilidad del proceso electoral en una situación - la primera vez- de aguda contienda política entre los partidos de oposición y el PRI.

A las irregularidades y críticas del proceso electoral de 1988 se debe que el nuevo presidente Salinas, desde su discurso de toma de posesión, el 1 de diciembre de ese mismo año, anunciara el Acuerdo Nacional para la Ampliación de la Vida Democrática, con el compromiso de proceder enseguida a la elaboración concertada de nuevas leyes electorales que desataran de una vez por todas los nudos que impedian la cabal democratización del régimen: la legalidad, la imparcialidad y la credibilidad del proceso electoral desde su organización hasta su cómputo final. Tres serán las reformas electorales, emprendidas por el gobierno de Salinas (1990, 1993 y 1994), al calor de las objeciones y presiones de los partidos de oposición y de la inteligencia crítica.

\section{Reformas electorales durante el gobierno de Carlos Salinas de Gortari}

El gobierno de Salinas abrió con el primer hecho de alternancia política, al reconocerse el triunfo del Partido de Acción Nacional (PAN) ${ }^{39}$ en el Estado fronterizo de Baja California. 1989 es así el inicio real de la transición democrática mexicana. A su vez, el primer gran triunfo de la oposición generó confianza en que la democratización del régimen era un proceso en marcha y una meta alcanzable.

La primera reforma electoral del gobierno salinista, en 1990, aprobada por el PRI y el PAN, produjo una nueva legislación: el Código Federal de Instituciones y Procedimientos Electorales (COFIPE). Los puntos más controvertidos de la legislación anterior existente habían sido el control que el poder ejecutivo seguía ejerciendo en la preparación, desarrollo y vigilancia del proceso electoral y la llamada cláusula de gobernabilidad ${ }^{40}$, que confería la mayoría en la Cámara de Diputados al partido que obtuviera el 35 por 100 de la votación total.
El COFIPE de 1990 estableció la creación del Instituto Federal Electoral (IFE) como la máxima autoridad electoral, que estaría presidida por el gobierno y se integraría con representantes del poder ejecutivo y legislativo y de los partidos políticos. Se consideró la inclusión de los ciudadanos (Consejeros Magistrados ${ }^{41}$ ) como el balance entre los actores gubernamentales y las organizaciones partidistas. El IFE ejercería sus funciones en todo el territorio nacional a través de 32 delegaciones, una para cada entidad federativa y el D.F., y de 300 subdelegaciones, una por cada distrito electoral. La autoridad del Instituto estaría a cargo de un Consejo General, presidido por el secretario de Gobernación, y tendría una dirección ejecutiva para fines de gerencia administrativa y apoyo técnico. Otro importante avance en la legislación de 1990 fue la creación del Tribunal Federal Electoral, que se encargaría de dirimir conflictos y controversias electorales y reforzaría el control sobre la legalidad de los actos y las resoluciones del organismo encargado de las elecciones. Eliminó el controvertido proceso de autocalificación de los senadores y diputados de sus elecciones, y creó el Registro Nacional de Ciudadanos para actualizar el padrón electoral.

Con dichas reglas se llevaron a cabo las elecciones federales de 1991, en las que el partido dominante, el PRI, recuperó las posiciones perdidas tres años antes. Sin embargo, la nueva ley electoral aún no dejaba conformes a las diversas fuerzas políticas, particularmente al Partido de la Revolución Democrática (PRD) ${ }^{42}$, que insistían en la sobrerrepresentación que introducía la cláusula de gobernabilidad, se oponian al control que todavía tenía el gobierno en la organización y dictaminación electoral, y denunciaban las condiciones de inequidad en la competencia electoral. Fue entonces necesario reformar por segunda vez el COFIPE para desahogar estas objeciones cruciales.

La segunda reforma estableció un más equitativo acceso de los partidos políticos a los medios de comunicación. En lo referente a financiamiento acordó establecer fuentes transparentes para la obtención de recursos por parte de los partidos y fijó límites a los gastos de campaña. Prohibió además todo financiamiento que proviniera de los gobiernos federal, estatal o municipal, ${ }^{43}$ de las dependencias y entidades públicas, de extranjeros, ministros de cultos y asociaciones religiosas y de organizaciones internacionales.

La reforma de 1993 mejoró asimismo la representatividad política del Congreso. Se estableció una nueva fórmula para el Senado que ampliaba las oportunidades de los partidos políticos al establecer cuatro senadores para 
cada Estado en lugar de dos, tres por mayoría relativa y uno para la primera minoría. El nuevo sistema entró en vigor en las elecciones de $1994^{44}$, por lo que el número de senadores se duplicó de 64 a 128. Incluso, en lo que respecta a la Cámara de Diputados, integrada por 500 miembros (300 electos por el principio de mayoría relativa y 200 a través del de representación proporcional) se eliminó la llamada cláusula de gobernabilidad.

Como complemento de las medidas anteriores, se procedió a levantar por segunda vez un nuevo padrón electoral y se emitió una credencial de elector con fotografía para responder a las objeciones de que el padrón contenía sospechosamente duplicaciones y eliminaba selectivamente a ciudadanos inclinados a la oposición.

A partir de enero de 1994, a raiz del levantamiento armado en Chiapas y del asesinato del candidato presidencial del PRI, Luis Donaldo Colosio, se presentó una circunstancia inédita en la política nacional, caracterizada por la incertidumbre y el riesgo político. La opinión pública se llenó de análisis pesimistas que preveían escenarios que iban del caos a un gobierno interino de mansición. Lo relevante en estas circunstancias fue el papel desempeñado por los partidos politicos que empezaron entonces a matizar su discurso beligerante y a buscar puntos básicos de acuerdo con el fin de evitar que las elecciones del 21 de agosto de 1994 fueran el inicio de una desestabilización de enormes daños para la nación.

Decisivo fue el Acuerdo para la Paz, la Justicia y la Democracia, firmado por partidos y candidatos presidenciales el 27 de enero de 1994. El acuerdo incluía una serie de medidas para garantizar tanto la equidad y civilidad en las campañas electorales, así como la organización imparcial y confiable del proceso y la jornada electoral. Sobre todo, dejó abierta la posibilidad de avanzar hacia una tercera reforma electoral, que creara condiciones todavía más convincentes de que las elecciones ocurrirían bajo el sello de la legalidad, la imparcialidad y la equidad. De ese acuerdo, tres meses después, surgieron nuevas e importantes modificaciones que abarcaron el código penal que tipificó 17 delitos electorales.

Las reformas constitucionales y del COFIPE llevadas a cabo en 1994 son importantes al menos por dos razones. En primer lugar, porque es la primera vez que logran el consenso de todos los partidos, incluído el $\mathrm{PRD}$, que se había resistido a aprobarlas en años pasados; segundo, porque establece una nueva composición de los órganos de autoridad electoral en la que seis consejeros ciudadanos independientes y apartidistas -electos por la Cámara de Diputados a propuesta de los partidos y no del presidente- se vuelven mayoritarios y determinantes en la toma de decisiones en el seno del Consejo General del IFE ${ }^{45}$. Por último, las reformas ampliaron el campo de acción de los observadores nacionales y aceptaron la presencia de los visitantes extranjeros.

Además de las reformas anteriores, el IFE impulsó en los últimos meses acuerdos que mejoraron las condiciones de confiabilidad y equidad del proceso electoral. Las nuevas medidas fueron: disminuir en cinco veces el tope de los gastos de campaña; llevar a cabo auditorías externas del padrón para garantizar su confiabilidad; crear una fiscalía especial para perseguir los delitos electorales; seleccionar, mediante un procedimiento de doble insaculación, a los ciudadanos que se harían cargo de la mesa directiva de las casillas electorales; emitir boletas electorales con talón foliado para controlar el cómputo de los votos; suspender las campañas publicitarias de los programas de PROCAMPO y PRONASOL -dos programas sociales que la oposición impugnaba como clientelares y favorecedores al PRI- durante un lapso de veinte días previos a las elecciones.

El contexto de incertidumbre abierto a partir de 1994, los recuerdos del resultado electoral de 1988 y las reformas electorales que terminaron incorporando la totalidad de las propuestas hechas por los partidos de oposición, alentaron la especulación de que los probables resultados de las elecciones presidenciales serían adversos al PRI y darían paso a la alternancia política, iniciándose efectivamente la transición democrática en México.

El día 22 de agosto se conocieron finalmente los resultados preliminares de una de las elecciones que más expectativas y escenarios había creado, bajo la mirada vigilante de aproximadamente 1.000 visitantes extranjeros y 50.000 observadores nacionales. Las cifras oficiales, respaldadas por encuestas de salida y sistemas de conteo rápido, dieron el triunfo al candidato del PRI, Ernesto Zedillo, con el 50.18 por 100 de los votos, seguido del PAN (centro derecha) con el 26.69 por 100 de los votos, y del PRD (izquierda) con el 17.08 por 100.

Como nunca antes, se comprobó una altísima presencia del electorado en las casillas, que rebasó no solamente los promedios nacionales de años atrás, sino que situó a México en los niveles más altos de participación electoral del mundo, al alcanzar más del 77 por 100 de votación respecto a la lista nominal. Los resultados electorales echaron abajo mitos, creencias y argumentaciones. Se vino abajo la tesis según la cual a mayor votación de ciudadanos correspondía un menor número de votos para el PRI; se sacudió también la creencia de 
que la limpieza electoral pasaba necesariamente por la derrota del PRI y se desacreditó la afirmación sobre el deterioro político paulatino y constante del PRI. Sobre todo, zozobró la tesis central de varios críticos, según la cual el triunfo del PRI tenía como base el fraude electoral.

\section{Reformas}

\section{constitucionales: hacia un Estado de Derecho}

Aunque el Estado mexicano se ha configurado como un vigoroso Estado nacional, no ha podido todavía consolidarse como un auténtico Estado de Derecho. Los esfuerzos por alcanzar un gobierno de leyes, imparcial, honesto y eficiente son todavía insuficientes para salvar la distancia entre el país legal y el país real. Uno de los efectos más benéficos del proceso de democratización emprendido ha sido justamente el (re)descubrir colectivamente el valor político del Derecho, la igualdad ante la ley, la exigencia de autoridades imparciales. Apreciar que quien elige el gobierno democrático elige antes el gobierno de leyes.

Durante el gobierno del presidente Salinas se respondió a las demandas populares de justicia y legalidad con avances en la construcción de un Estado de Derecho; los más importantes fueron: a) la creación de la Comisión Nacional de Derechos Humanos (CNDH), órgano independiente, fiscalizador de los actos del gobierno y protector de los derechos humanos contemplados en el orden jurídico; b) la modificación del marco legal del campo mexicano, que buscó dar mayor certidumbre jurídica a un sector sacrificado en aras de la industrialización; y c) la reforma constitucional del artículo 130, cuyo propósito era establecer las nuevas relaciones entre el Estado y las Iglesias, sin menoscabo de la tradicional convicción laica del Estado y la libertad religiosa.

\section{La CNDH y la emergente cultura de los derechos humanos}

Son hechos conocidos en México la indolencia y parcialidad en la procuración y administración de justicia, la violación de los derechos ciudadanos y la corrupción inaceptable en ciertas áreas del sector público. Frente a esto, el gobierno mexicano decidió establecer, a semejanza del modelo escandinavo del ombudsman o del defensor del pueblo en el modelo español, una institución encargada de la protección, promoción, estudio y divul- gación de los derechos civiles: la Comisión Nacional de Derechos Humanos. No bastaba la existencia de la ley ni su incipiente o parcial cumplimiento; era necesario una instancia diferente de las ya instituidas que fuera capaz de defender activamente los derechos de los ciudadanos.

Creada por acuerdo presidencial el 5 de junio de 1990, la Comisión se concibió, según el presidente Salinas, como instrumento de la sociedad para vigilar y auxiliar a las autoridades en la observancia de la ley y enla protección de las garantías individuales. Desde sus inicios, a pesar de que el marco jurídico original la definía como un órgano desconcentrado de la Secretaría de Gobernación, la CNDH adquirió un alto grado de independencia que le otorgó un amplio prestigio en la sociedad mexicana, ávida de justicia y de respeto a la legalidad. Una muestra reciente de su reputación fue el haber otorgado al titular de la Comisión la delicada tarea de conciliar y lograr la paz en el conflicto armado de Chiapas.

Su fructifera y notable experiencia condujo a que el 22 de enero de 1992 se modificara el artículo 102 de la Constitución, en el que se facultaba al Congreso y a las legislaturas locales para que, dentro de sus respectivas jurisdicciones, establecieran organismos de protección de derechos humanos. La nueva disposición constitucional también dio a la CNDH el carácter de organismo descentralizado con personalidad jurídica y patrimonio propios; la facultad de emitir recomendaciones públicas, autónomas, no vinculatorias e informales; la no competencia en asuntos electorales, laborales y jurisdiccionales.

Mediante una intensa labor de promoción, capacitación y divulgación, la CNDH logró en poco tiempo constituirse en un instrumento educativo de la sociedad al pugnar por una cultura política de la legalidad en un país que, por muchas razones históricas, terminó atrapado por arbitrariedades y componendas. El elevado número de quejas atendidas por la Comisión, la fundación de las Comisiones Estatales de Derechos Humanos en las entidades federativas y el nacimiento de organizaciones no gubernamentales protectoras y defensoras de derechos civiles, son los ejemplos más significativos de la interiorización e incorporación de esta prometedora cultura de los derechos bumanos en la conciencia del ciudadano mexicano. La gran tarea pendiente de los siguientes gobiernos, por tanto, es la reforma del Poder Judicial, que depure la administración de justicia y culmine la construcción de un gobierno plenamente legal.

\section{El campo mexicano}

El artículo 27 constitucional, producto máximo de la revolución agraria de 1910, prohibió el latifundio y orde- 
nó el reparto agrario, así como la restitución de tierras y aguas a toda comunidad que las hubieran perdido. Estas medidas, plenamente justificadas en su momento, generaron con el paso del tiempo problemas y vicios expresados en el minifundismo improductivo, la falta de certeza en la tenencia de la tierra y la venta o renta de parcelas ejidales ${ }^{46}$ contra la ley agraria.

Estas distorsiones, entre lo formal y lo real, tuvieron efectos sobre la productividad del campesino, la cual era 2.5 veces menor al promedio nacional y 4.3 veces inferior a la del obrero en 1982. El salario anual promedio per cápita de la población ocupada en el campo, por tanto, era inferior al de otras actividades económicas. Además, en 1988 y 1989 el PIB del sector agrícola mostró tasas de crecimiento negativas de 3.9 y 4.2 por 100 respectivamente.

La Secretaría de Agricultura y Recursos Hidráulicos (SARH) y el Instituto Nacional de Estadistica, Geografía e Informática (INEGI) reconocieron que el 52.4 por 100 de la superficie agrícola nacional era de subsistencia, el 40.5 por 100 era cultivada por métodos tradicionales y sólo en el 7.1 por 100 se utilizaban técnicas avanzadas. Asimismo, en 1988 el 23 por 100 de la fuerza nacional de trabajo laboraba en el campo, pero ésta contribuía con apenas el 7.7 por 100 del PIB. Ante este panorama y la nueva orientación de la política comercial, el gobierno del presidente Salinas se planteó la necesidad de modernizar el aspecto juridico-institucional que orientaba y definía las relaciones en el campo mexicano.

El propósito de las modificaciones al artículo 27 constitucional fue el de otorgar seguridad legal a los productores con el fin de promover la capitalización del campo. La reforma, que reafirma la prohibición del latifundio, otorga una mayor certeza en la tenencia de la tierra y consolida los tipos de propiedad (privada, ejidal y comunal) en busca de una mayor productividad y justicia en el agro mexicano.

El cambio constitucional también dio por terminado el reparto agrario, una expectativa incansable de las masas campesinas e indígenas y una obligación pública que por décadas se consideró la quintaesencia de la Revolución Mexicana. El reparto no podía ser permanente debido a que el crecimiento de la población rural había ocasionado la fragmentación de la tierra que imposibilitaba el acceso al crédito y la tecnología. Para fomentar la capitalización en el campo se establecieron las condiciones legales que permitieron la inversión directa de las sociedades mercantiles, organismos que antes de las reformas no podían adquirir, poseer o administrar fincas rústicas y, por lo mismo, estaban imposibilitadas a invertir en actividades agrícolas. La reforma también contempló la protec- ción de las formas tradicionales y comunitarias de tenencia de la tierra existentes en el país (principalmente de los ejidatarios y comuneros) y reconoció la capacidad de los productores de decidir sobre el uso de sus parcelas.

Las modificaciones a la Constitución y a la Ley Agraria permitieron la creación de los Tribunales Agrarios y de la Procuraduría Agraria. Ambas instituciones operan desde 1992 con el propósito de abatir el rezago en los certificados de la propiedad rural y proteger a los propietarios de las tierras. Así, la nueva realidad jurídico-institucional en el campo pretende inscribirlo en el mercado competitivo tanto interno como externo. El proceso, sin embargo, deberá complementarse con políticas crediticias, de asistencia técnica y apoyos a la comercialización libre de los productos del campo, terreno donde todavía hay mucho por hacer.

\section{Redefinición de las relaciones Estado-Iglesias}

Al llegar a la presidencia, Salinas de Gortari abrió la discusión sobre la libertad religiosa y las relaciones del Estado con las Iglesias, otro tema tabú, dado el comportamiento polémico de la Iglesia mexicana frente al Estado mexicano a lo largo del siglo xIx e inmediatamente después de la Revolución. Luego de tres años de discusiones y debates, en 1992 se aprobó casi por unanimidad la reforma al artículo 130 constitucional que superaria la situación de simulación y que modificaría normas que eran letra muerta por la imposibilidad de ponerlas en práctica, además de que contravenían abiertamente cualquier declaración de derechos humanos fundamentales.

Con las reformas constitucionales se logró que, por primera vez, sacerdotes y demás ministros de cultos religiosos obtuvieran derecho a votar, al tiempo que la legislación les restringía el derecho a ser votados para cargos públicos de elección. Asimismo, las Iglesias obtuvieron personalidad jurídica, con lo que fueron reconocidas formalmente por el Estado, permitiendo así superar una simulación que por años se había guardado entre las partes. Por último, abrió la posibilidad para que las asociaciones religiosas pudieran dedicarse a las labores de enseñanza en forma legal, siempre y cuando se ciñeran a los planes y programas de estudio dictados por el gobierno.

Los fundamentos del Estado laico, por su parte, permanecieron. La separación de las Iglesias, la supremacía del poder civil, la subordinación de todos a la legalidad, la igualdad ante la ley de todas las Iglesias y asociaciones religiosas, además del imperativo de garantizar las libertades de conciencia y promover la tolerancia, son algunos de los principios que le dan vida al laicismo estatal. Incluso permaneció vigente la estricta prohibición de que las Iglesias intervengan en los asuntos políticos. 
La reforma constituyó, de esta manera, un avance profundamente significativo en las relaciones del Estado con la sociedad, en su actualización y mejoramiento. La legislación, hasta entonces vigente, era la de la Constitución de 1917 y la Ley Reglamentaria de 1923, pensadas ambas para principios de siglo y no para nuestros días. Las actitudes, que en su momento justificaron la adopción de disposiciones legales y políiticas hostiles frente a la Iglesia católica, perdieron su sentido.

\section{Conclusiones}

La reforma del Estado mexicano aún no ha terminado. Sin duda, los avances en la democratización del régimen y en la liberalización económica han originado una nueva relación entre Estado y sociedad, bajo el signo de una mayor autonomía y participación social en los asuntos públicos. Han modificado también la estructura y el número de las organizaciones de la Administración Pública, así como su patrón de gestión. Pero todavía quedan muchas cosas por hacer en diversos órdenes. Fundamental es concluir la obra maestra del Estado de Derecho y del gobierno de leyes, llevar a su conclusión la democratización del régimen y abrir el proceso de un mejor balance entre el gobierno nacional y los gobiernos locales conforme a la naturaleza federal de la república.

En estos últimos meses, a lo largo de la campaña electoral e inmediatamente después de conocidos los resultados, se ha ido configurando una agenda común en la que son más las convergencias que las divergencias, entre los partidos políticos. A diferencia del pasado, lleno de tensiones, desconfianzas y enfrentamientos, hoy los líderes de los partidos han manifestado explícita y promisoriamente su voluntad de dialogar para encontrar los acuerdos políticos básicos que den el sustento del consenso a la agenda común. La novedad no consiste en identificar los puntos prioritarios a tratar, sino en la cooperación política para llevarlos a cabo, la cual parece finalmente tomar forma, a pesar de que los principales actores políticos difieran sobre sus instrumentos, tiempos y alcances.

La agenda tiene dos capítulos: una agenda institucional y una agenda de políticas. La primera tiene que ver con lo que es hoy un reclamo nacional: efectiva división de poderes, contrapeso democrático al tradicional presi- dencialismo, una reforma a fondo del poder judicial en busca de una procuración e impartición de justicia honesta e imparcial, un balance efectivo entre los tres órdenes de gobierno -federal, estatal y municipal- con el tema del federalismo fiscal en punta. Y, en lo que concierne a la Administración Pública, es hora de iniciar una profunda modernización administrativa que haga posible en los hechos la gestión eficiente y equitativa que se espera de un Estado reformado. Después del adelgazamiento de su estructura y de la introducción de nuevas formas de regulación de la economía y de atención a los problemas sociales, sigue pendiente la tarea de reformar organizaciones y procesos administrativos, precisamente para que el nuevo estilo de gobernación y gestión muestre su capacidad de resolver problemas y conflictos.

La segunda agenda, la de políticas, no es menos importante. Los cambios ocurridos son hoy una plataforma más sólida y prometedora para atender los viejos y nuevos problemas del país. Las políticas de estabilización no se han traducido todavía en crecimiento económico. La apertura y globalización económica, que ha obligado a las empresas sobrevivientes a volverse productivas y competitivas, todavía no han creado los empleos e ingresos que se esperan de ellas. Y enfrente siguen dolorosamente presentes las cuestiones de la pobreza y la desigualdad injusta, particularmente en las zonas rurales y en las comunidades indigenas, no obstante las políticas activas y novedosas de asistencia, desarrollo y seguridad social. El desafío consiste en probar que la reforma del Estado tiene sentido y eficacia para reformar las condiciones de vida social, tan angostas y fatales para millones de ciudadanos.

Resurge así, una vez más, el tema del desarrollo económico y social, que ha acompañado permanentemente a México. Y bien vistas las cosas, más allá de la cortina de humo de las recientes polémicas prejuiciadas o argumentadas sobre la supuesta naturaleza neoliberal de la reforma, el desarrollo económico y social ha sido el objetivo de fondo de la transformación del Estado mexicano. Se ha buscado armar una nueva economía política que sea también economía social. Y esta idea regulatoria de la política y la Administración Pública, mexicana y no, seguirá conduciendo el trabajo interminable de dar respuestas, muchas y modificables, a las cuestiones públicas y a las necesidades sociales.
- Profesor-investigador del Centro de Estudios Internacionales del Colegio de México. Director de la Fundación Siglo XXI Luis Donaldo Colosio.

' Esta ideología se construyó a partir del levantamiento armado de 1910, se plasmó en la Constitución social de 1917 y se consolidó con la creación de un partido de Estado todo incluyente. La ideología reivindicó la nacionalidad mexicana en un país que, después de la Revolución, se encontraba muy fragmentado. Lo popular es la base del Estado social que México y sus instituciones siempre han enaltecido (actualmente, en la ideología del liberalis- 
mo social del Partido Revolucionario Institucional (PRI) que ha sido el partido oficial del Estado desde 1929).

' En 1976-1977 el gobiemo emprendió el primer intento de autocorreción gubernamental: la reforma político-administrativa de José López Portillo. Por un lado, se pensó que, ante el crecimiento expansivo del Estado, se podría ordenar, responsabilizar y hacer más eficiente el sector público, central y pamestatal a través de procedimientos racionalizadores de organización y métodos de gestión. La reforma administrativa previó competencias, sectorizaciones, globalizaciones, desconcentraciones administrativas, delegaciones de autoridad y agilizaciones de trámites. Por otro, la reforma política, emprendida en 1976, fue una liberalización controlada de la competencia política, particularmente por el lado de la izquierda, debido a las convulsiones magisteriales y estudiantiles, al sindicalismo independiente y a los focos de guerrilla urbana y campesina. Ambas reformas constituyeron el primer esfuerzo de reforma del Estado, que muy pronto mostró sus limites y se perdió en la clebacle de fin del sexenio lópezportillista (1976-1982). En lo administrativo, fue un ordenamiento y no un redimensionamiento; en lo político, fue un esfuerzo por desactivar las presiones del momento y no una democratización integral del sistema.

${ }^{3}$ El régimen posrevolucionario también se cimentó en otra fuente de legitimidad, de origen legal: la democracia política. Ésta, sin embargo, fuẹ descuidada sin gandes cosios políticos hasta antes de la década de los ochenta. CRESPO, J. A. (1992), p. 19.

- El estilo de gestión pública se caracterizaba por: 1) el predominio del gobierno federal sobre los otros órdenes de gobierno; 2) el desempeño de in gestión pública como fuente primera de la legitimidad política del gobierno; 3) la amplia autonomía y discrecionalidad del gobierno y, en consecuencia, escasa participación, discusión y concertación ciudadana en la formulación de la agencla político-administrativa y en la elección e implementación de las políticas públicas; 4) el énfasis en la gestión a través de jerarquias personalizadas, de empleados de confianza, de directivos discrecionalmente asignados en función de adhesiones y compromisos personales; 5) la gestión clirecta de las políticas por razones de superior control y también de mayor visibilidad de la acción gubernamental en busca de consenso y apoyo; y 5) el descuido de la dimensión de costos de las decisiones públiCas. AGUillAR, L. (1992), pp. 131-134.

' El exceso de liquidez en los mercados financieros internacionales, aunado a una elevada inflación genemlizada en las economías industrializadas, provocó un descenso en la tasa real de interés (LIBOR) que se situó en niveles reales negativos. Al mismo tiempo, se presentó un shock petrolero que incrementó el precio promedio por barril. Ambas condiciones permitieron la contratación de empréstitos externos y el gran crecimiento de las exportaciones de petróleo. De 1977 a 1982 el endeudamiento externo mexicano (global) saltó de 30,3 a 87,6 millones de dólares; el del sector público pasó de 18,6 a 51 millones de dólares (equivalente a 36,5 por 100 del PIB). Las exportaciones de crudo representaron aproximadamente el 75 por 100 de las exportaciones totales y el 20 por 100 de los ingresos del gobierno.

- Sin recursos externos y con un fuerte déficit en la balanza de pagos, México se vio obligado a suspender el servicio de la deuda externa desde septiembre hasta diciembre de 1982. Su monto total ascendia a 92 mil 408 millones de dólares que representaba el 49 por 100 del PIB y la estructura de vencimientos se encontraba recargada excesivamente en el corto plazo: el 46 por 100 debía pagarse en un período no mayor a tres años y el 27 por 100 dumnte 1983.

' El arículo 115 enlista los siguientes servicios públicos: agua potable, alcantarillado, alumbrado público, limpieza, mercados y centrales de abasto, panteones, rastros, calles, parques y jardines y seguridad pública y tránsito. Estos servicios pueden ampliarse o reducirse en función de sus condiciones territoriales y socioeconómicas, así como de su capacidad administrativa y financiera. En cuanto a las fuentes de ingresos, el citado articulo establece: los rendimientos de sus bienes, las contribuciones sobre la propiedad inmobiliaria, las participaciones federiles correspondientes y los ingresos derivados de la prestación de los servicios públicos a su cargo. Cabe agregar que por respeto al principio de legalidad contenido en el arículo 31 fracción IV, se exige que los ingresos tributarios municipales sean aprobados por la Legislatura de los Estados.

- Las áreas estratégicas de exclusividad del Estado, conforme al art. 28 constitucional, son: acuñación de moneda y emisión de billetes, correos, telégra- fos, radiotelegrafía y comunicación vía satélite, petróleo e hidrocarburos, petroquímica básica, minerales radiactivos y energía nuclear, electricidad, ferrocarriles y "las actividades que expresamente señalen las leyes que expida el Congreso de la Unión". Cabe agregar que las áreas prioritarias carecen de un criterio constitucional preciso o de un procedimiento político administrativo aceptado que permita definir con certeza su campo e importancia. Hay margen para la discrecionalidad de la decisión e interpretación.

${ }^{9}$ Factores como la apreciación del tipo de cambio real, el moderado crecimiento de la producción y la expansión de las exportaciones no petroleras estimularon al sector empresarial a realizar pagos anticipados de su deuda externa, lo que aunado a la incertidumbre por la caída del índice de la Bolsa Mexicana de Valores, en el mes de octubre, provocó una importante reducción de las reservas internacionales. Así, el 18 de noviembre de 1987, con el fin de proteger el nivel de reservas, el Banco de México se retiró del mercado cambiario del dólar y ocasionó que su cotización aumentara alrededor del 33 por 100 (de 1.700 pesos/dólar a 2.258), agudizándose de esta manera el problema inflacionario.

${ }^{10}$ La pérdida del poder adquisitivo de los salarios fue la consecuencia inexorable de la caída de los términos del intercambio que enfrentó el programa de estabilización. Por una parte, se permitió una mayor competitividad de las exportaciones provenientes de los sectores intensivos en mano de obra y se impulsó a la industria maquiladora; por otra, se consolidó la contracción de la demanda. Aspe, P. (1993), p. 26.

"El superávit primario fue entendido como la diferencia entre la recaudación y el gasto, excluyendo de éste último el pago de intereses de la deuda pública (interna y externa).

${ }^{12}$ Es importante recordar, que las medidas de los programas de ajuste anteriores (el PIRE y el PAC) avanzaron en la creación de las condiciones necesarias para el éxito de un programa de estabilización con medidas heterodoxas.

13 El diseño e instrumentación de un programa heterodoxo en México no sólo presentaba dificultades técnicas, sino también un riesgo de pérdida de credibilidad. Además del ajuste fiscal, se requería que los salarios reales y los márgenes de utilidad para el sector privado se ajustaran de manera congruente, lo que era imposible realizar sin un acuerdo entre las autoridades y la población. Para el análisis empírico sobre la influencia de las expectativas en el comportamiento macroeconómico, véase ASPE, P., y JARQUE, C. (1985).

14 Véase ASPE, P. (1993)

${ }^{15}$ El PSE se caracterizó por el establecimiento de las anclas nominales, la realineación de los precios clave en la economía, y la instrumentación de la política fiscal y monetaria restrictivas.

${ }^{16}$ La tasa del impuesto sobre el ingreso corporativo (impuesto sobre la renta para sociedades mercantiles) pasó de 37 por 100 a 36 por 100 , mientras que la nueva estructura aplicable a personas físicas estableció una tasa marginal máxima de 35 por 100. La tasa del impuesto al valor agregado (IVA) pasó de 15 a 10 por 100 . También se continuó con la eliminación de las bases especiales de tributación para incorporar a los causantes menores y a los sectores especiales como agricultura y transporte.

${ }^{17}$ El análisis de la política de gasto se realiza más adelante en el apartado de la desincorporación de empresas públicas.

18 Tiempo después (1992) se cambió su nombre por el de Pacto para la Estabilidad, la Competitividad y el Empleo.

19 Durante el PECE se puso énfasis especial en reducir la inflación anualizada a un digito, recuperar el crecimiento económico por arriba del incremento poblacional, reducir las transferencias de recursos al exterior como prerrequisito para volver a crecer en forma sostenida con estabilidad de precios y en profundizar en el cambio estructural de la economía mexicana.

${ }^{20}$ A comienzos de la llamada crisis de pagos en 1982, la deuda externa mexicana estaba compuesta de la siguiente manera: a) deuda del gobiemo con la banca comercial, el 50 por 100; b) deuda del gobierno con instiuciones financieras oficiales, el 30 por 100 ; y c) la deuda de empresas privadas, el 20 por 100 .

"Se permitió a los bancos acreedores seleccionar entre tres opciones: a) reducir el principal en 35 por 100; b) disminuir la tasa de interés y fijarla en 6,25 por 100; y c) para los bancos que no tomaran ninguna de estas opciones prestar recursos frescos por el 25 por 100 del saldo de la cartera mexicana. 
22 La reducción de la deuda pública permitió al gobierno mexicano disminuir considerablemente las transferencias netas al exterior: del 5,7 por 100 del PIB en 1988 llegaron al (-) 0,3 por 100 en 1989. Asimismo, el servicio de la deuda, que en el período 1982-1987 fue de 9,5 por 100 del PIB en promedio, disminuyó a 6,0 por 100 en 1988-1991. Adicionalmente, el paquete financiero negociado también tuvo efectos indirectos muy importantes, como el fortalecimiento de la confianza de los distintos agentes económicos. ${ }^{23}$ A causa de la crisis, en 1988 el salario real disminuyó un 50 por 100 con respecto a 1982; el 18 por 100 de las familias mexicanas percibía menos del salario mínimo y vivian en condiciones de extrema pobreza, y casi el 50 por 100 de las familias tenían ingresos mensuales de menos del equivalente a dos salarios mínimos (Consejo Consultivo del Programa Nacional de Solidaridad 1991).

${ }^{24}$ Véase GONZilez, T. (1991)

`Véase AGUILAR, L. (1991).

* Desincorporación es la expresión que suele emplear el gobierno mexicano para incluir todos los procesos de redimensionamiento: liquidación o extinción (de las entidades sin viabilidad económica o con objetivos alcanzados), fusión (para mejorar el uso de los recursos), transferencia (a los gobiernos estatales de empresas prioritarias de importancia regional), venta (de empresas no estratégicas ni prioritarias que, por su viabilidad económica, pueden ser de interés para el sector social o privado). En el fondo, es una cuidadosa expresión para no denotar ni enfatizar la privatización.

$"$ Esta decisión debe haber obedecido a restricciones internas, presiones internacionales, cálculos pragmáticos de gobierno, pero indudablemente también a la convicción del círculo intimo de decisión. El proceso de suce. sión, que favoreció a Carlos Salinas de Gortari, puso de manifiesto la convicción de la clase política en una nueva concepción de la rectoría gubernamental y en la necesidad de un nuevo modelo de desarrollo.

${ }^{28}$ Véase ASPE, P. (1993), pp. 154-189.

' La Ley Federal de Trabajo determina los cargos considerados de confianza. La contratación, promoción y despido de este tipo de empleados se realiza sin intervención de la Federación de Sindicatos de Trabajadores al Servicio del Estado.

${ }^{30}$ Estos precios permanecieron constantes durante el primer bimestre de 1988 para que, con base en el acuerdo de la segunda concertación, se incrementaran gradualmente.

${ }^{31}$ Entre diciembre de 1987 y diciembre de 1988, el arancel más alto descendió de 100 por 100 a 20 por 100 y el número de arículos sujeto a restricciones cuantitativas pasó de 1.200 a 325 , representando el 21,2 por 100 de las importaciones totales.

32 La desregulación del mercado, al buscar la liberación de las fuerzas competitivas, debía cumplir dos objetivos básicos: en primer lugar, sentar las bases para maximizar la competencia potencial; en segundo lugar, crear una infraestructura de incentivos adecuada para la toma de decisiones. Lo primero implica que todos los actores económicos ruvieran las mismas posibilidades de entrar en los mercados; lo segundo, luchar contra las asimetrías de información. LEvY, S. (1993).

"La idea de la reforma del Estado tuvo su primera y más aniculada expresión en el Primer Informe de Gobierno (1 de diciembre de 1989). Fue después desarrollada con fines explicativos pero sin avances conceptuales, en un artículo de Carlos Salinas de Gortari, (1990) "Reforma del Estado" en Nexos, abril, pp. 27-32. Las teorías principales han sido repetidas o parafraseadas en otros discursos presidenciales o en el discurso de sus funcionarios.

${ }^{*}$ Mientras en el Primer Informe de Gobierno el referente primero es la Revolución Mexicana, en el artículo de 1990 el referente es la Constitución Políica. Se arma este esquema de razonamiento con el fin de probar que la reforma del Estado recupera las funciones públicas que la Revolución y la Constitución le habian otorgado.

35 SHCP-SECOGEF (1994), p. 57

${ }^{36}$ En 1972 el gobierno federal se convirtió en el propietario mayoritario del capital social de Telmex, la tercera empresa más grande de México y la empresa más importante que cotizaba en la Bolsa Mexicana de Valores Actualmente tiene más de 6 millones de lineas instaladas y 64 mil emplea- dos. Su capital se componía antes de dos tipos de acciones, las acciones que podrían ser suscritas por cualquier inversionista mexicano o extranjero y las acciones de exclusiva propiedad gubernamental, que eran equivalentes al 51,4 por 100 del capital. El gobierno, también propietario de Acciones A, tenía el control de la empresa y era el propietario para fines de negociación laboral y salarial con un sindicato muy activo y cohesionado.

${ }^{37}$ Telmex estaba sujeto a un régimen fiscal distinto al resto de las empresas públicas. Dicho régimen no se fundamentaba en criterios de operación o desempeño de la compañia; se basaba en un conjunto de gravámenes ad boc.

${ }^{8}$ El esquema de estructuración financiera de Telmex consistió en uniformar las acciones. Se creó un nuevo tipo de acciones llamadas "L", para aumentar el capital social. La emisión de acciones L fue a razón de 1,5 acciones por cada acción "A" y "AA". Estas últimas serían las únicas que tendrían derecho a voto. Por consiguiente, el gobierno era propietario de todas las acciones AA y de 3.244 millones de acciones L, correspondientes al 51 por 100 del capital. Para finales de 1990 la estructura de Telmex quedó integrada por la serie A de acciones que correspondian al 19,6 por 100 del capital y al 49 por 100 del voto (o acciones comunes); la serie AA que corresponde al 20,4 por 100 del capital y al 51 por 100 del voto; y al 60 por 100 de acciones $L$ en capital, pero sin voto. El grupo ganador de la subasta fue el grupo Carso, encabezado por el Sr. Carlos Slim, la Southwestern Bell y France Cable and Radio, que adquirieron el total de las acciones gubernamentales AA y, por tanto, el control de la empresa. De los 1.756 .6 millones de dólares pagados por estas acciones, el grupo Carso mexicano aportó el 51 por 100 y el resto fue de las compañías extranjeras en forma casi proporcional, de manera que el grupo mexicano tuvo el control mayoritario de la empresa. Rocozinski, J. (1993).

39 El PAN se creó en el año 1939 con fundamentos ideológicos inspirados en el liberalismo y la doctrina social de la Iglesia. Sin embargo, no fue sino hasta principios de los ochenta cuando obtuvo presencia real en el escenario político nacional. Desde entonces, ha emprendido una trayectoria electoral ascendente que lo ha llevado a ganar alcaldias importantes y tres gobernaturas estatales. En las pasadas elecciones del 21 de agosto, el PAN afirmó su carácter de segunda fuerza política nacional.

'0 Dicha cláusula se creó en la reforma electoral de 1986 y se mantuvo en la de 1990. Por tal se entiende la necesidad de incrementar la representatividad de los partidos de oposición en el Congreso, pero sin perder la capacidad de gobernar, de llevar adelante las iniciativas del ejecutivo por causa de bloqueos y estancamientos en el debate parlamentario.

"Los Consejeros Magistrados debian cumplir con los requisitos para ser Ministro de la Suprema Corte de Justicia de la Nación y no haber ocupado cargo de elección popular o de dirigencia paridista en los cinco años anteriores.

${ }^{42}$ En 1988, como resultado de la escisión en el PRI de la llamada Corriente Crítica, encabezada por Cuauhtémoc Cárdenas y P. Muñoz Ledo, surgió el Frente Democrático Nacional FDN, coalición de varios partidos de izquierda impopulares. El Frente fue el antecedente de lo que más tarde sería el PRD, partido integrador de corrientes de izquierda y del nacionalismo revolucionario tradicional.

" Como prueba de parcialidad en la competencia política, la oposición denunciaba que el PRI gozaba del privilegio de utilizar fondos públicos para actividades paridarias

* En estas elecciones estaba prevista la renovación de la mitad de la Cámara Alta que antes constaba de 64 senadores; sin embargo, las reformas recientes eliminaron esa fórmula, por lo que el 21 de agosto de 1994 se eligió a tres senadores: dos por mayoria y uno por primera minoria. En 1997 se elegirá a 32 senadores para ocupar el cargo por tres anos solamente y en el año 2000 se renovará la Cámara de Senadores completamente.

" El Consejo General del IFE se integra además por cuatro representantes del Poder Legislativo (dos diputados y dos senadores, uno de mayoría y uno de minoría respectivamente) y por el secretario de Gobernación que es el presidente del Consejo General.

${ }^{4}$ El ejido es una figura jurídica creada después la Revolución de 1910. Está constituido por tierras comunales con el especííco objetivo de cultivar la tierra. Sin embargo, los campesinos "ejidatarios" no poseen poder de enajenación ni dominio de las propiedades. 


\section{Bibliografia}

Aguilar Vilianueva, Luis F. (1991): "Solidaridad: tres puntos de vista" en Consejo Consultivo del Progma Nacional de Solidaridad, Solidaridad a debate. México, El Nacional, pp. 127-137.

(1992): "Gestión gubernamental y reforma del Estado", en Mauricio Merino Huerta (coord.), Cambio politico y gobermabilidad. México, Colegio Nacional de Ciencias Políticas y Administración y Consejo Nacional de Ciencia y Tecnologia, pp. 131-147.

(1992a): "Las reformas mexicanas: hechos y agenda" en Barry B. Levine (comp.), El desafio neoliberal. Bogotá, Colombia, Norma, Pp. 193-221

ASPE ARMELLA, PEDRO (1993): El camino mexicano de la transformación económica. México, Fondo de Cultura Económica (F.C.E.).

y Carlos Jarque (1985): "Expectativas racionales: un modelo trimestral para la economía mexicana", El Trimestre Económico, 52 (1985), pp. 649-682.

Consejo Consultivo del Programa Nacional de Solidaridad (1991): El combate a la pobreza, $2^{\mathrm{B}} \mathrm{ed}$. México, El Nacional.

Cordera Campos, Rolando y Jose Wold)enberg (1994): "Al cierte", Cuaderno de Nexos, mayo, pp. 2-3.

CRESPO, JOSf: ANTONIO (1992): "Crisis económica: crisis de legitimidad", Soledad Loneza (comp.), en México. Auge, crisis y ajuste. México, F.C.E., tomo 1: Los tiempos del cambio, 1982-1988, pp. 15-33.
Madrid Hurtado, Miguel De la (1989): Sexto informe de gobierno. México, Presidencia de la República.

Gonzalez Tiburcio, Enrique (1991): "PRONASOL: hacia la nueva síntesis", Cuaderno de Nexos, octubre 1991, pp. 10-12.

Jarque, Carlos M. y Luis Téllez K. (1993): El combate a la inflación. México, Grijalbo.

LEVY, A. SANTTAGO (1993): "La apenura comercial y el programa de desregulación económica en México", en María Elena Vázquez Nava (coord.), La Administración Pública contemporánea en México. México, F.C.E., pp. 116-127.

NuÑez JimÉnez, ARTuRo (1993): La reforma electoral de 1989-1990. MéxiCO, F.C.E.

ReBOlledo, JuAn, (1993) La reforma del Estado en México. México, F.C.E.

ROGOZINSKI, JACQUES, (1993) La privatización de empresas paraestatales. MéxiCo, F.C.E.

Secretaría de Hacienda y Crédito Público y Secretaría de la Contraloría General de la Federación (1994): Desincorporación de Entidades Paraestatales. México, F. C.E.

WOLDENBERG, JOSÉ (1994): "1994: Elecciones y legalidad", Cuaderno de Nexos, marzo, pp. 51-61. 


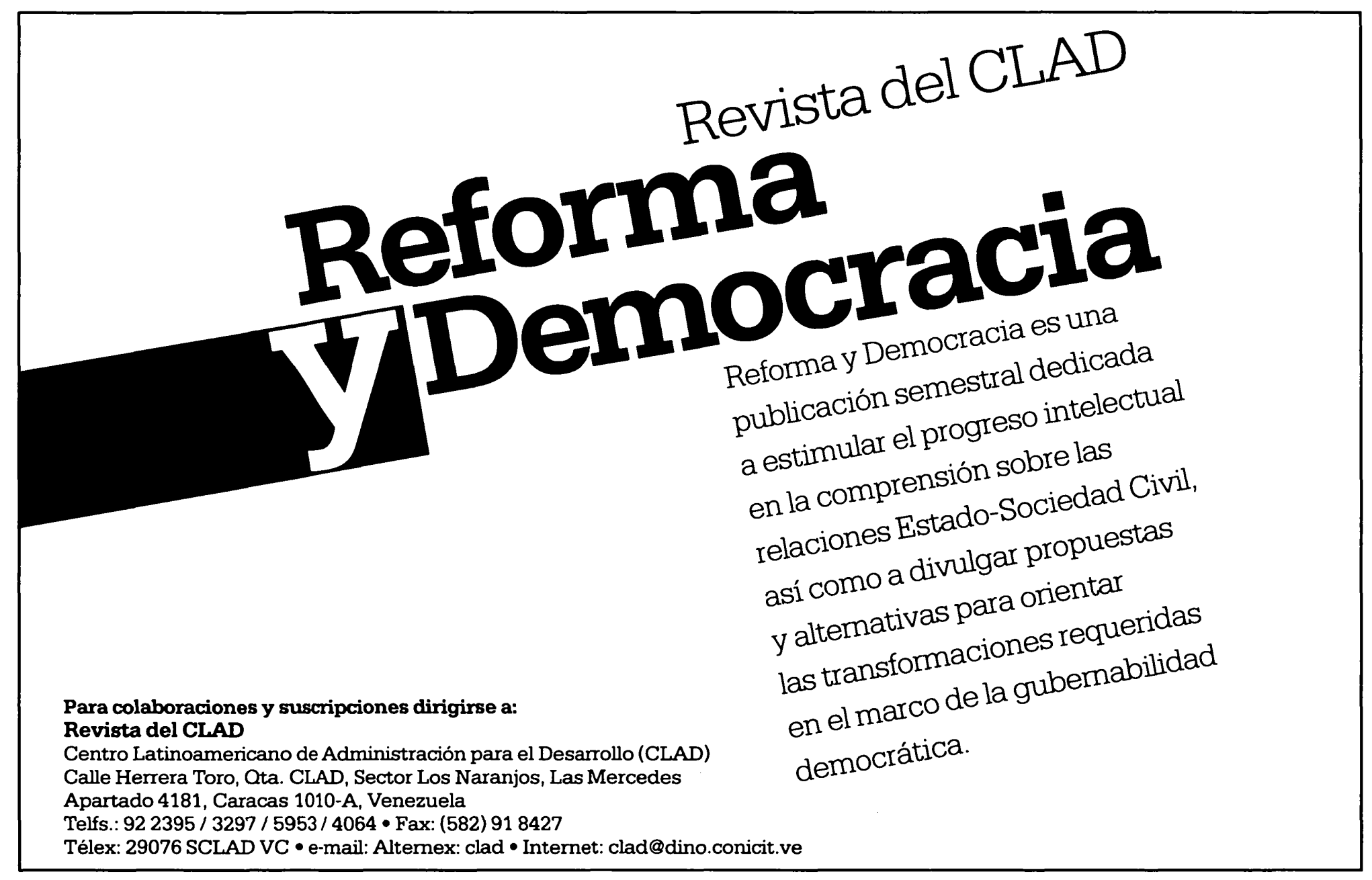

